\title{
Load Management Alternatives to Transmission and Distribution Construction: Toledo - Wren Case Study
}
J. E. Englin
J. J. Tawil
M. S. Klan
J. G. De Steese
A. J. Lyke
R. C. Tepel

December 1987

Prepared for

Bonneville Power Administration

under a Related Services Agreement

with the U.S. Department of Energy

Contract DE-AC06-76RLO 1830

Pacific Northwest Laboratory

Operated for the U.S. Department of Energy

by Battelle Memorial Institute 


\title{
DISCLAIMER
}

This report was prepared as an account of work sponsored by an agency of the United States Government. Neither the United States Government nor any agency thereof, nor Battelle Memorial Institute, nor any of their employees, makes any warranty, expressed or implied, or assumes any legal liability or responsibility for the accuracy, completeness, or usefulness of any information, apparatus, product, or process disclosed, or represents that its use would not infringe privately owned rights. Reference herein to any specific commercial product, process, or service by trade name, trademark, manufacturer, or otherwise, does not necessarily constitute or imply its endorsement, recommendation, or favoring by the United States Government of any agency thereof, or Battelle Memorial Institute. The views and opinions of authors expressed herein do not necessarly state or reflect those of the United States Government or any agency thereof, or Battelle Memorial Institute.

\author{
PACIFIC NORTHWEST LABORATORY \\ operated by \\ BATTELLE MEMORIAL INSTITUTE \\ for the \\ UNITED STATES DEPARTMENT OF ENERGY \\ under Contract DE-AC06-76RLO 1830
}

\begin{tabular}{|c|c|}
\hline \multirow{2}{*}{\multicolumn{2}{|c|}{ Printed in the United States of America }} \\
\hline & \\
\hline \multirow{4}{*}{\multicolumn{2}{|c|}{$\begin{array}{c}\text { National Technical Information Service } \\
\text { United States Department of Commerce } \\
5285 \text { Port Royal Road } \\
\text { Springfield, Virginia } 22161\end{array}$}} \\
\hline & \\
\hline & \\
\hline & \\
\hline \multirow{2}{*}{\multicolumn{2}{|c|}{$\begin{array}{l}\text { NTIS Price Codes } \\
\text { Microfiche } \mathrm{A01}\end{array}$}} \\
\hline & \\
\hline \multicolumn{2}{|c|}{ Printed Copy } \\
\hline & Price \\
\hline Pages & Codes \\
\hline $001-025$ & $\mathrm{~A} 02$ \\
\hline 026-050 & $\mathrm{A} 03$ \\
\hline $051-075$ & A04 \\
\hline $076-100$ & A05 \\
\hline $101-125$ & $A 06$ \\
\hline $126-150$ & $\mathrm{~A} 07$ \\
\hline $151-175$ & $\mathrm{~A} 08$ \\
\hline $176-200$ & A09 \\
\hline $201-225$ & A010 \\
\hline $226-250$ & A011 \\
\hline $251-275$ & $\mathrm{~A} 012$ \\
\hline $276-300$ & $\mathrm{~A} 013$ \\
\hline
\end{tabular}


PNL-5931

UC-95

LOAD MANAGEMENT ALTERNATIVES TO

TRANSMISSION AND DISTRIBUTION

CONSTRUCTION: TOLEDO-WREN CASE STUDY
J. E. Englin
M. S. Klan
A. J. Lyke
J. J. Tawil
J. G. De Steese
R. C. Tepel

December 1987

Prepared for Bonneville Power Administration under a Related Services Agreement with the U.S. Department of Energy under Contract DE-ACD6-76RLO 1830

Pacific Northwest Laboratory

Richland, Washington 99352 
I 


\section{EXECUTIVE SUMMARY}

This is a report on the Conservation in Lieu of Construction (CILOC) study which was a task in the Customer System Efficiency Improvement (CSEI) Assessment Project. This project was conducted by Pacific Northwest Laboratory (PNL) for the Office of Conservation, Bonneville Power Administration (BPA). The principal objective of the CSEI Project was to assess the potential for, and impacts of, conservation in the BPA service area.

The objectives of this CILOC study were to first develop, and then apply, a methodology to examine the potential for direct load control to defer the construction of additional transmission and distribution capacity needed to accommodate load growth in a given area. These two objectives were first met by synthesizing two pieces of software, Loadcalc and Microcast, (a) and applying the resultant forecasting model to a test case. This test case considered the plan to add a $230 \mathrm{KV}$ reinforcement line between Toledo and Albany, Oregon. This case allowed the testing and evaluation of the methodology developed in the first phase of the study.

The CILOC methodology was based on the end-use forecasting approach incorporated in the Loadcalc and Microcast systems. However, neither piece of software was capable of performing the analysis required in this study. Both included questionable underlying assumptions. Some important problems that were discovered in the course of the first phase of the study included:

- the assumption that conservation is unable to change the hour of system peak

- an inability to separate effects of conservation programs from improved efficiency of appliance replacement stocks

- the existence of identical end-use load shapes across all residential sectors

- the lack of integration of the commercial or industrial sectors into the conservation assessment model.

(a) Commercially available software systems produced by Applied Energy Group, Inc. of Key Garden Hills, New York. 
To partially compensate for these difficulties, Loadcalc and Microcast were combined. The synthesis of these two resulted in a methodology which retained the end-use basis for forecasting. One remaining difficulty was tre inability to differentiate the effects of conservation programs from change; in the efficiency of replacement appliance stock. This assumption is too deeply imbedded in Loadcalc to allow its relaxation in the scope of this project. As a result, a maintained assumption in the following analys is is that replacement stocks will have the same appliance efficiencies as existing stocks. Examination of national time-trend data on appliance efficiencies indicated that this assumption is unrealistic. Another problem was an inability to use different end-use load shapes for the different residential sections. Metered data from other projects, such as ELCAP, indicates quite clearly that load shapes from diverse types of housing differ substantially. This software constraint on the analysis has unknown implications for the results.

By using an end-use methodology, the ability to examine the effect of controlling a particular end-use was retained. Since the project is concerned with examining the effect of changes in individual appliance load shape on system load shape, this was an important consideration in the selection of modeling techniques.

Data for the application came from a variety of sources. Much of the needed data was quite utility specific, and required the direct acquisition of data from both of the utilities, Consumer's Power P.U.D. and Central Lincoln P.U.D., that serve the Toledo-Wren area. Among the data gathered on these visits were:

- information on appliance saturations

- peak day and month

- number of residential accounts

- number of conmercial accounts

- average energy use by end use.

Other sources included the 1970 and 1980 U.S. Census, EPRI Information Sheets, the BPA Ten-Year Facility Construction Plan, and other PNL reports developed by the CSEI Project.

The methodology developed operates in the following way. First, the model takes each end-use load shape and weights it by the number of residential 
customers having a given appliance, and then aggregates to generate the load shape of each appliance for the total residential sector. The contuercial sector's contribution is estimated from a lighting load shape and a residual load shape. The industrial load shape was created from industry specific information about load factors and historical demand for energy. Each of these were also weighted by the number of customers and aggregated to obtain their relative contribution to the system load curve. Changes in the forecasted system load shape are estimated by examining how a conservation policy would effect the particular sector's load shape, and then reaggregating the new shapes.

Examining a specific case in this framework involves selecting a study area and a set of load controls. The Toledo-Wren Reinforcement Project was selected for study because of its relative simplicity and the accessibility of empirical data. To develop the CILOC methodology, the study considered three demand-side options: water heater control, ceramic space heaters, and commercial lighting efficiency improvements. Since each of these options changes the end-use load shape, they have an impact on system load shapes. By appropriate control of the shape of these end-uses, the growth in peak demand can be slowed. This results in lowered transmission capacity requirements in any given year.

The effects of these controls on the need for transmission construction was evaluated first with the commercial software. Controls were found to delay the need for new transmission construction in all cases. Water heater controls delay construction just over 1 year. Ceramic space heaters delay construction nearly 2.5 years. A combined residential water heater and ceramic space heater program delays construction $31 / 3$ years. Commercial lighting has a negligible, though positive delay on transmission construction timing.

The difficulties discovered in the course of applying commerciallyavailable software in this analysis motivated the development of new customdesigned software. The implementation of the Toledo-Wren Test Case using the new software allowed greater levels of detail and more sensitivity analysis at lower cost than was possible with the commercial software. However, the model, as finally configured, preserves most of the methodology of the original approach. Differences include the modeling of the industrial sector within 
the regular software and the disentanglement of conservation and appliance stock change effects. The new software includes several enhancements that 11 low the original methodology to be fully implemented.

Two conservation programs were examined with the new software. In addition, the combined effect of both programs was considered. All three alter. natives had the capability to make noticeable reductions in the rate at which peak demand grew in the Toledo-Wren service area. Most effective was the combined case, where both water heater control and ceramic space heater programs together could preserve the adequacy of current transmission facilities for up to 9 years. The next most effective program was the water heater coitrol program. This program could defer the need for additional transmission capacity for 7 years. The ceramic space heater program was quite close also with deferments between 4 and 8 years depending on the industrial growth scenario. The results indicate clearly that, in cases where there is isolated load growth. conservation may be a viable alternative to transmission and distribution facility construction. 


\section{CONTENTS}

EXECUTIVE SUMMARY ..................... i

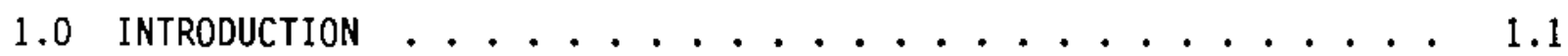

1.1 GENERAL STUDY PROCEDURE . . . . . . . . . . . 1.2

1.2 SPECIFIC TEST CASE: TOLEDO-WREN . . . . ....... 1.3

2.0 DATA NEEDS AND AVAILABILITY . . . . . . . . . . 2.1

2.1 DATA NEEDS . . . . . . . . . . . . . . 2.1

2.2 Generally available data SOURCES . . . . . . . . . . 2.2

2.3 POTENTIALLY AVAILABLE DATA SOURCES . . . . . . . . 2.2

3.0 METHODOLOGIES FOR CONSTRUCTING LOAD SHAPES ......... . . 3.1

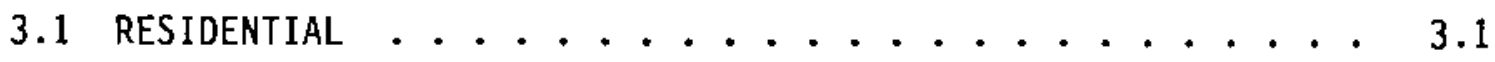

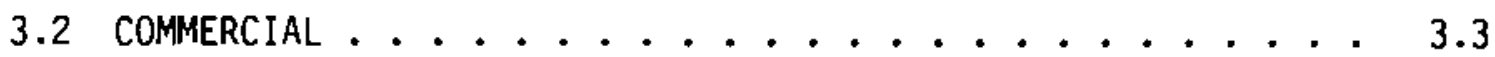

3.3 INDUSTRIAL . . . . . . . . . . . . . . . 3.4

3.4 LOAD SHAPE TRANSFERABILITY . . . . . . . . . . 3.5

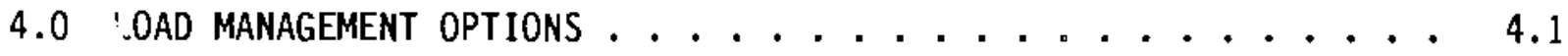

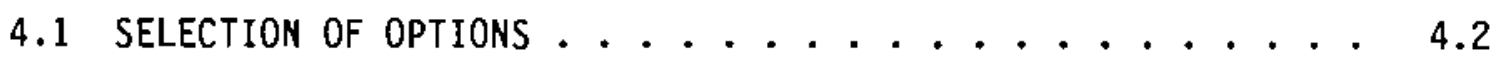

5.0 TOLEDO-WREN CASE STUDY $\ldots \ldots \ldots \ldots . \ldots . \ldots . \ldots . \ldots . \ldots$

5.1 END USE LOAD CURVES ......................... 5.2

5.2 NUMBER OF RESIDENTIAL ACCOUNTS ................. 5.3

5.3 RESULTS ............................ 5.10

5.3.1 Base Case Scenario ............ 5.11

5.3.2 Water Heater Control .......... 5.11

5.3.3 Ceramic Room Heater Program ........... 5.12

5.3.4 Combined Program: Water Heater and Space
Heater Control . . . . . . . . . 5.14

5.3.5 Commercial Lighting Progran ......... 5.15 
5.4 CONCLUSION . . . . . . . . . . . . 5.15

6.0 ASSESSMENT OF RESULTS USING COMMERCIAL SOFTWARE . . . . . 6.1

7.0 SOFTWARE DEVELOPMENT $\ldots \ldots \ldots \ldots . \ldots \ldots$

7.1 SOFTWARE REQUIREMENTS AND DEVELOPMENT $\ldots \ldots \ldots . \ldots . \ldots$

7.1 .1 Load-Shape Module . . . . . . . . 7.2

7.1 .2 End-Use Module ................ 7.3

7.1 .3 Summary Module . . . . . . . . . . 7.4

7.2 TOLEDO-WREN TEST CASE APPLICATION OF THE NEW SOFTWARE . . 7.5

7.2.1 Residential Sector ........... 7.5

7.2.2 Commercial Sector............. . 7.7

7.2 .3 Industrial Class .................. $7 . \varepsilon$

7.2 .4 Sunnary Module . . . . . . . . . . 7.ع

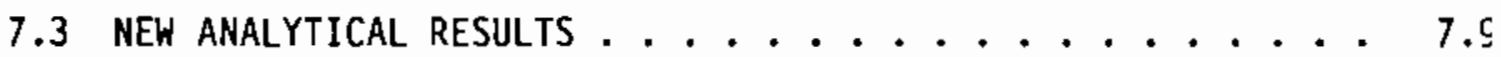

7.3.1 Ceramic Space Heater Program ........ 7.5

7.3.2 Water Heater Control Program ......... 7.10

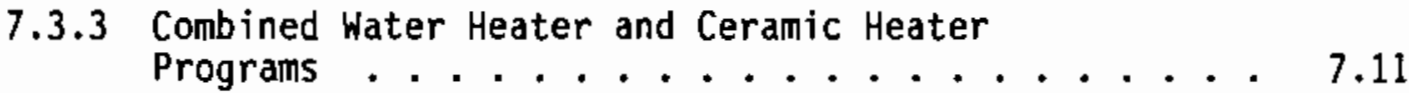

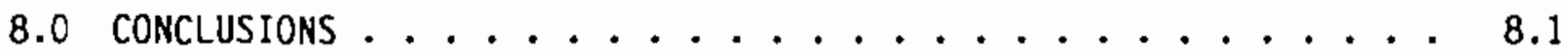

APPENDIX A - CASE STUDY DATA SOURCES . . . . . . . . . A.1 


\section{FIGURES}

1.1 BAP Transmission Construction Plan Including the Toledo-Wren Reinforcement Project . . . . . . . . . . . . 1.4

5.1 Normalized Water Heat Residential Load Curve . . . . . . . . 5.3

5.2 Normalized Space Heat Residential Load Curve . . . . . . . . . 5.4

5.3 Normalized Other Uses Residential Load Curve . . . . . . . . 5.5

5.4 Normalized Total Residential Load Curve . . . . . . . . . 5.6

5.5 Total System Load Curve . . . . . . . . . . . . . . 5.12

5.61990 Residential Sector Water Heater Load Curve . . . . . . . . 5.13

5.71990 Residential Sector Space Heater Load Curve . . . . . . . . 5.14

5.81990 Commercial Sector Load Curve . . . . . . . . . . . . . 5.15

7.1 Basic Alignment of New Software Modules when Applied to

7.2 Peak Deferment Resulting from the Ceramic Room Heater Program ....................... 7.10

7.3 Peak Deferment Resulting from Water Heater Control Program . • 7.11

7.4 Peak Deferment Resulting trom Combined Water Heater and Ceramic Heater Programs . . . . . . . . . . . . 7.12 

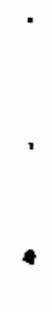


\subsection{INTRODUCTION}

This task of the Customer System Efficiency Improvement (CSEI) Assessment Project focused on the development of a methodology that can be used to assess the feasibility and economic reasonableness of implementing load management as an alternative to building additional transmission and distribution (T\&D) capacity. Such an assessment can be referred to as a conservation-in-lieuof-construction (CILOC) study. The methodology developed was guided by, and applied to, a specific test case in the Toledo-Wren, Oregon area where a new $230 \mathrm{KV}$ transmission line had been planned. The objective was to determine whether construction of the planned line can be economically delayed--possibly indefinitely--by taking conservation-related actions, including the use of direct load controls.

Forecasted load growth in an area is one of the primary reasons for the planning of new transmission capacity. In areas where positive load growth is expected, eventually electricity consumption will exceed the capacity of the existing transmission system. By examining the sectoral nature of the load in the area and by disaggregating key end-uses of electricity within each sector, some estimate can be obtained of the potential for conservation and/or peak shifting. This alteration of the system sha ' can result in the reduction in demand, and delay the need for new transmission facility construction. Sectors worthy of examination include: residential, commercial, industrial, and agricultural (especially irrigation). End-uses to be considered vary according to the sector.

The ability of load management options to reduce loads and modify shapes at the end-use level allow management at the aggregated system level to reduce system peaks at any given time. Thus, the potential exists, through the judicious application of load management options, to delay the date when the transmission system capacity threshold is attained. The benefits of delaying transmission construction (and associated expenditures) can then be weighed against the costs of implementing and maintaining the load management programs. 
A methodology to perform evaluations of this type in a case study environment, while maintaining a conceptual framework which could apply in many different actual cases, is the major developmental objective of this task.

\subsection{GENERAL STUDY PROCEDURE}

The development of the CILOC methodology involved several analytical steps. The region affected must be identified in terms of end-users affect ad by transmission construction and others for whom load management options will have an impact. This can be done by accounting for the service area suppliad by the existing and planned T\&D system.

Outage conditions and their accomanodations should also be considered. The applicability of CILOC in a given area can be affected by the rationale for new construction. It could make a considerable difference in defining the study area whether the new transmission facility is primarily intended is a reliability addition, or a load growth addition.

The composition of residential, comnercial, industrial, and agricultural loads drives the mix of conservation and load management options to be eval.uated. The identification of loads has two components. The first is the definition of the appropriate geographic area for study. A decision as to whether a neighboring city should be part of the study area may drastically affect the penetration of permanent electric space heating equipment, for example. This penetration, in turn, may be crucial in determining the ultinate viability of direct load control.

The second aspect of load identification is the development of representative load curves for each of the key end-uses by sector. Disaggregation of both shapes and load levels must be achieved. Data sources for this activily vary widely according to each specific case: possible sources include metered end-use data, feeder data, and large customer load data collected by the utility.

It is likely that data availability and quality will vary considerably across the geographic area of interest. Data may have to be transferred from surrounding areas to the one under study. Issues of regional weather varia. tion, population size, and composition (e.g., resort areas versus agricultural 
areas), industrial patterns, among others will make key differences when assessing the relative applicability of one area's data to another area.

The range of potential load management options must be identified, and particular options selected. Load management options and scenarios should then be characterized in terms of their technical feasibility, costs, potential penetration, and effect on loads shape. The load management scenario provides a description of the option(s) to be implemented, the terms of its introduction to the consumer's environment, its overall cost, the magnitude of savings or peak shifting for individual loads, and the impacts on system load level and shape.

After load management scenarios are developed, it is possible to compare the base case consumption of electricity with consumption following the implementation of management. This stage of the evaluation process is built up from the individual sector end-use loads established earlier. Properly constructed load management scenarios typically show that the capacity of the transmission system is reached some time later than would be anticipated in the base case. The benefits and costs of corresponding delay in transmission construction can then be estimated.

\subsection{SPECIFIC TEST CASE: TOLEDO-WREN}

The CILOC Assessment Methodology was developed by studying a representative case for which a transmission facility construction project had been identified. The test case used in this effort was the Toledo-Wren Reinforcement Project. This project would increase transmission capacity to the central coast of Oregon. It was shown in BPA's transmission construction plan for the period 1985-1994 as a tentative New Start in Fiscal Year (FY) 1987 with a planned energization in 1989. Construction would consist of 1) a $42 \mathrm{mile}$ $230 \mathrm{KV}$ line from Albany to Toledo; 2) an additional $230 \mathrm{KV}$ Power Circuit Breaker at Toledo; 3) a 12.5 MVA $230 / 24.9 \mathrm{KV}$ transformer at the Burnt Woods Substation; and 4) appropriate power system control and protective gear. Figure 1.1 shows the proposed action. The cost estimate for the project was $\$ 10.75$ million in 1985 dollars. 


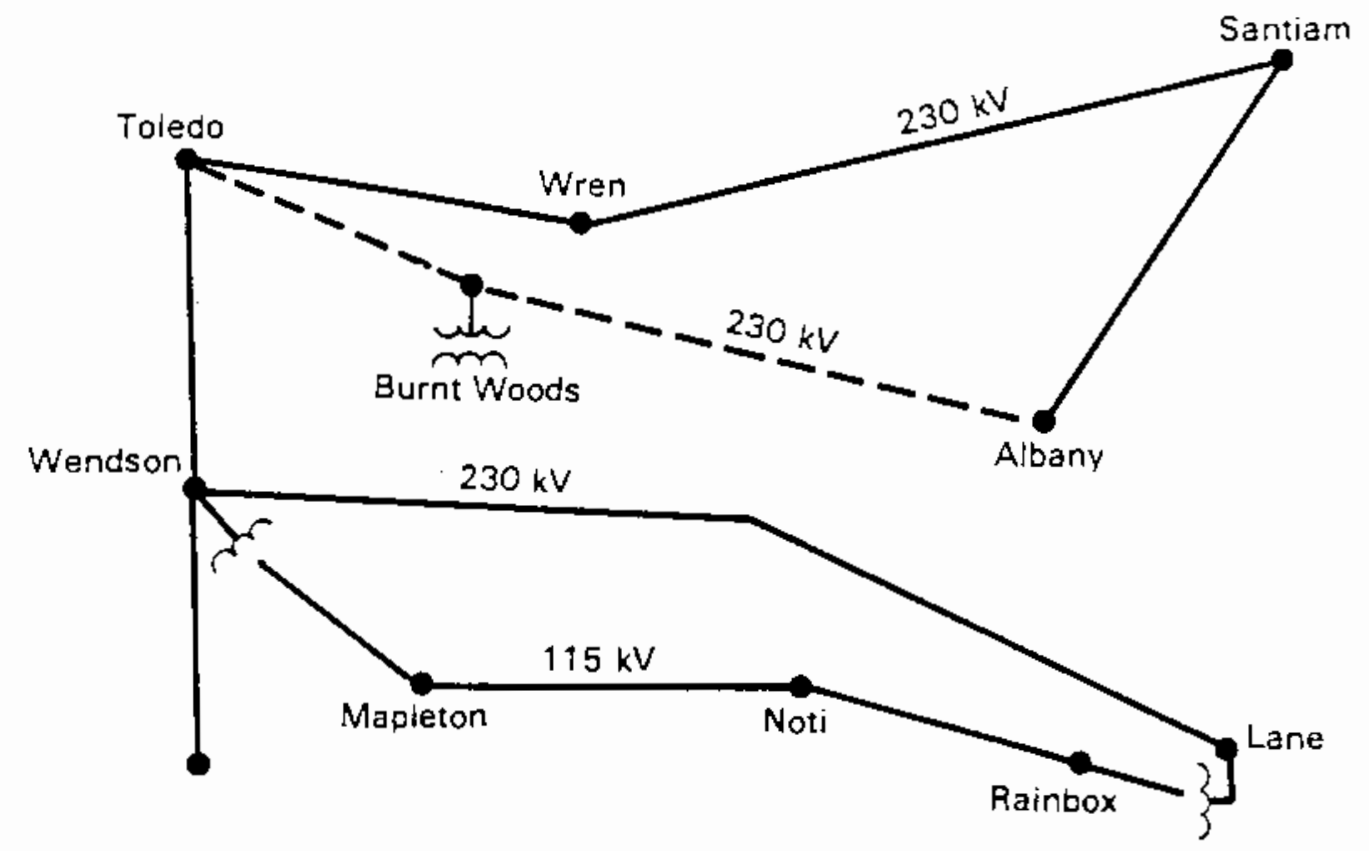

Existing Lines

- - New Construction

FIGURE 1.1. BPA Transmission Construction Plan Including the Toledo-Wren Reinforcement Project

The original justification for the Albany-Toledo line was to prevent overloads and low voltages in the event of an outage in either the LaneWendson or the Santium-Wren $230 \mathrm{kV}$ circuits, as illustrated in Figure 1.1. Two outage scenarios were considered in BPA analysis that justified the reinforcement project. First, an outage on the Wren-Santium line would cause low voltage in the Toledo and Wren areas. Secondly, an outage between Lane and Wendson on the $230 \mathrm{KV}$ line would similarly cause low voltages at Toledo and Wren, and, in addition, overload the parallel $115 \mathrm{KV}$ circuit between Lar $\mathrm{e}$ and Wendson.

The 1989 energization, as originally planned, would accommodate the January 1990 peak load projected from BPA's 1982 forecast. Loads in the Toledo-Wren area have not grown as expected. The 1985 revision of the load forecast indicates that the need for reinforcement has been deferred, at leist into the mid-1990's. 
Despite its deferred status, the Toledo-Wren project when considered in the context of the 1982 forecast, remains a representative and relatively uncomplicated test case for exercising the CILOC assessment methodology developed in this study. 


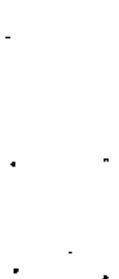




\subsection{DATA NEEDS AND AVAILABILITY}

This section summarizes data needs and availability for a load management case study. Section 2.1 describes data needed to assess load management options in a system planning framework. Section 2.2. identifies sources of data that are generally available. Section 2.3 describes data that may or may not be available depending on the study area.

\subsection{DATA NEEDS}

Information needs include customer class loads, end-use load, end-use load shape, number of customers, and load components. It is desirable to obtain load forecasts in as much detail as is available, as well as the assumptions behind the forecasts.

Load data should, at least, be separable into residential, conmercial, and industrial categories. Agricultural loads should also be considered in the case of a sumner-peaking utility. Further disaggregation for every sector is also essential. Residential loads should be separated according to housing size and type, commercial loads according to type and size of business, and industrial loads by major plant. In addition, sector loads should be separated according to end-use (zich as space heating, water heating, other appliances) wherever possible.

Time-of-day data are needed in order to construct load shapes. Shape information is needed in order to estimate the effects of conservation and load management options on system peaks. End-use metered data are preferable. If there are no metered data for the area under study, either meters can be installed, or data can be borrowed from another area and normalized for differences in weather and customer characteristics. Because of the great expense of metering, the latter option will often be the more appropriate path.

Data normalization requirements introduce extensive additional information needs regarding customer characteristics and weather. Data normalization must occur if metered data are to be transferred from one area to another. In effect, one must quantify differences between customers and weather in the metered location and the study location. 


\subsection{GENERALLY AVAILABLE DATA SOURCES}

Utilities are generally able to provide numbers of customers by customer class, loads, and load forecasts. In the Pacific Northwest, all these data, as well as load forecasts, are provided by utilities to the BPA on BPA Form 980 . Many utilities prepare more detailed forecasts as well.

Weather information can be obtained from the National Climatic Data Certer (of the National Oceanic and Atmospheric Administration, Department of Commerce). Surface weather observations taken at weather stations throughout the country are reported to this data center where they are digitized and stored on magnetic tape. Long-run weather normals are available for each station as we1l. Maps showing the locations of weather stations may be obtained from the National Climatic Data Center.

The U.S. Bureau of Census, Department of Commerce, publishes detailed population and housing characteristics for every county and most cities. Information includes housing types, numbers of rooms, and potentially useful details, such as the presence of fireplaces.

Appliance saturations for residences in each utility service area have been compiled for Northwestern utilities by BPA. Saturations of electric space heat, water heat, air cond:ioners, and other appliances are available. National appliance saturations as well as standard appliance electricity usages are maintained by the Association of Home Appliance Manufacturers.

Assorted other, generally available, sources of information may be useful. Local Chambers of Comnerce often compile information about local manufacturing, numbers of hotel rooms, and local businesses. Numbers and kinds of businesses may also be extracted from the yellow pages of the local telephone directory.

\subsection{POTENTIALLY AVAILABLE DATA SOURCES}

Utilities may have very detailed information about their customers. Residential surveys, metering projects,. and special studies may all be available. As an example, Central Lincoln PUD was engaged in a total load, hourly profile metering experiment of both residential and commercial customers. 
While modest in scale, this information is an important way to verify the assumptions of this study. The possibility that microdata, specific to the area, is available, should be carefully examined.

County real estate assessor's offices have detailed data on housing characteristics. Assessor's data are part of public records. If records are maintained only in conventional file drawers, however, they may be too costly to be useful. On the other hand, some assessor's offices are now computerized. In such cases, one may be able to obtain all data on tape and/or sumary reports containing pertinent housing characteristics.

Industrial data about specific plants are generally proprietary. However, operators may be willing to discuss nonproprietary aspects of their plant's operation in some detail; in addition, operators are generally interested in load management options since they may increase the plant's operating efficiency. Other sources of industrial data are the Department of Comnerce (for throughput data), industry organizations (for typical operating practices). and equipment vendors, for typical electricity usage of major equipment. 


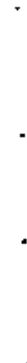




\subsection{METHODOLOGIES FOR CONSTRUCTING LOAD SHAPES}

Load management options generally affect not only the level of electricity usage, but also the timing. Further, some direct load control measures require in excess of $100 \%$ payback of the electricity deferred; others somewhat less. These measures are implemented on an individual customer basis. When all customer loads (residential, comnercial, industrial, and other) are aggregated to the system level, the impacts at the system level become apparent. Projecting these impacts in advance requires insight into 1) the composition of system load by sector on average, 2) end-use hourly patterns within sector, 3) seasonal variation and direct weather responsiveness (and other major exogenous factors), 4) and the overall coincidence of loads. In addition to the above requirements, the technology and program specific impacts of selected load management options must be quantified.

A major component of the required information is representative load curves (shapes) by sector and end-use, where appropriate. To the extent that modification of system peak is a goal of the analysis, it may be possible to limit investigation of load shapes to the winter months (for winter peaking areas) or surmer months (for summer peaking areas). This evaluation must be done carefully for areas where implementation of load management may chanç this fundamental focus. Generally speaking, and for the Toledo-Wren case study in particular, sector load shapes have been limited to residential, comnercial, and industrial. Sections 3.1 through 3.3 discuss issues associated with commercial and industrial load shapes, respectively. The last subsection provides a discussion of load shape transferability. Shape transfers are needed when actual are not available for the area of interest, but may be available for neighboring or similar areas.

\subsection{RESIDENTIAL}

Residential load is typically disaggregated into space heat, water heat, and residual categories. Such a classification is useful as long as the load management options can be adequately captured. Problems arise in areas with mixtures of gas and electric space heating equipment. For example, the responsiveness of a composite space heating load curve to heat pump cycling would 
be nearly impossible to calculate. In this example, more disaggregation is needed. The lesson is that the necessary level of disaggregation depends or the characteristics of the area under study. Comnitments to disaggregation levels should only be made after characteristics data are examined.

Once end-uses have been selected, other issues arise. These include penetration of the end-use, weather responsiveness, absolute contribution to overall load, and, of course, end-use load shape. Each of these items deperids on housing type, household composition, location within the study area, and a variety of other factors. At each step, decisions must be made about what detail to keep and what detail to discard (or assume) in the overall analysis.

The goal is to achieve residential end-use load shapes which are "representative" of the study area, and which make up a specific fraction of the overall load (to be calculated through penetration and population estimates). In most cases, for winter peaking areas, a winter representative end-use locd shape is probably sufficient. Whether a weekend-weekday distinction need be made depends on load levels and shapes observed or inferred for the area. It can occur that weekend loads do not coincide enough to drive system peaks, even though the absolute weekend levels may equal (or exceed) weekday loads. Again, decisions must be made at every step, based upon informed judgment ard the data available. The science of the study process as it pertains to loacl shapes is the ability to estimate, transfer, and aggregate the curves. The art is the ability to discern those factors where the incremental cost of additional refinement is matched or exceeded by the ultimate impact on study result sensitivities.

Typically, some metered load data is available by end-use, either for the study area or a related area. This historical data can be used to prodice representative curves when combined with weather and other consumption-related information. Transferability issues will be discussed in a later subsectior. It is useful here to comment on weather responsiveness of loads. This is commonly most evident for space heating load. Space heating is so responsive to the outside temperature that any short time series of load data should be viewed with suspicion. The problem is that if the weather during the measurement period is not representative of long-term area weather, then neither will the resulting load shape be representative. The usual way to deal with 
this problem is a series of techniques collectively known as weather normalization. Basically, weather normalization involves adjusting load data on an hourly basis to reflect the loads that would have occurred if the weather had been truly representative.

Weather normalization is a time-honored but controversial set of procedures. When using a representative class-by-class aggregation process (at the end-use level) to build system load shapes, weather nomalization is common and may be necessary. (Not all methods of load shape estimation and buildup would require formal normalization, however, this will be discussed in Section 3.4). Classes within an end-use provide a further level of breakdown. The exact classes employed depend on those where the largest difference occur. For some areas the dominant class distinction might be resident income; others might break out according to occupant ages; still others might best be subdivided based on structural characteristics such as the vintage of the dwelling. Generalizing from other areas and other metered data sets seems particularly useful in this context.

In sumary, end-uses, time periods, class subdivisions, weather adjustments, and population counts and penetrations must be selected. In some cases an analysis of existing data provides the proper assumption; in other cases the data are really insufficient. Judgments must be made at this step. Techniques are applied to generate representative curves. The representative curves are calibrated so that they aggregate up to the residential aggregate shape and Jevel (to the extent these things are known). Further aggregation with other sectors leads to system load and shapes.

\subsection{COMMERCIAL}

Because of the importance of space heating to residential loads, weatherrelated issues were very important in their analysis. Very small commercial establishments have the same properties, with a large portion of the peaking load attributable to space heating. Larger commercial establishments are less weather dependent, with much of the load going to lighting. The specific load shapes within these larger buildings is very business and schedule dependent. In other words, the consumption of electricity in a medium to large commercial building depends on what activities are occurring there, and when 
they are occurring. Restaurants, warehouses, offices, gas stations, etc., are all rather different in their electricity consumption patterns.

For a given building type, it is easier to transfer the metered results. from one location to another in the commercial sector than in the residential sector. This is due to the relative independence from weather. However, the quality of the aggregated comercial load shape depends greatly on the acculacy with which the commercial community can be characterized for the study area If telephone books can be collected to properly reflect the study area, then the yellow pages may provide an excellent source of information on the popu-. lation of commercial enterprises. The number of restaurants, hotels, etc., that exist in the area can be determined by counting the establishments. Other information may be available from Chambers of Commerce and County off:ces. With proper counts, a reasonable set of representative commercial curves carı be generated.

\subsection{INDUSTRIAL}

Industrial loads and load shapes are totally dependent on the specific industrial makeup of the area. Even a knowledge of the plants in an area is not really sufficient, however. One must take into account the products being made, the rates of productior. production schedules, production processes being employed, capacities for multiple fuel use, along with forecasts of all these factors. One advantage is that once these items are known or assumed, the resulting load information is often completely independent of the climate in the area under study. (The energy sent to some industrial processes is, however, related to the weather.)

With assumptions and data on the above, industrial loads can be aggreg;ted for the study area and a sector shape obtained. Analysis of the transmissicn and distribution system is often helpful with industrial loads, since some feeders may be dedicated to certain industrial customers. Total load data may be available for these feeders, providing a benchmark to work from for that piant. 


\subsection{LOAD SHAPE TRANSFERABILITY}

For each of the sectors discussed above, the transfer of data and knowledge from one geographical area to the study area is generally necessary; and the possibility of intertemporal transfers also exists. In the industrial sector, a meaningful transfer may not be possible without a detailed knowledge of the industrial base in the study region. Given that detailed knowledge, the data from specific industries of other regions may simply be used for the study area. Commercial transferability issues center on the small commercial--large conmercial mix. Small commercial buildings look much like residential buildings, and have similar transfer problems. Large commercial buildings are very type and schedule specific. If a proper categorization and count is achieved for this group, a direct transfer from another geographical area may be feasible.

The residential sector presents both the clearest problem and most potential use for transferability. Residential loads, being so weather dependent, are consequently very geography and time dependent. As a general rule, metered load data for one area cannot be directly applied to another area without a severe loss in accuracy. A variety of statistical and related methods have been developed for load data transfers; none appears to have been extensively tested to date. A fairly simple approach cai je taken. This involves weather and load data from a donor area, and weather data from the target or study area. Also important are data used to classify key groups in the samples. These classifications might focus on socioeconomic characteristics or structural characteristics (such as a house vintage).

Weather data are used to normalize the donor load data, and to adjust it for the weather in the study area. This is done separately for the different classes selected for evaluation. The separation of classes allows the analyst to account for different space heating load shapes in older and newer dwellings (for example), and to further account for the differences in vintage composition between the two areas. There are usually practical limitations to the number of classes which may be examined, based on limitations on the amount of load data available and concerns about its "representativeness" as the class sample size gets smatl. 


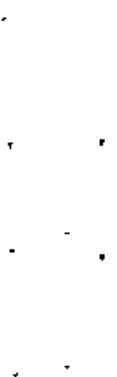




\subsection{LOAD MANAGEMENT OPTIONS}

In certain circumstances, demand side or load management can be an important alternative to the construction of new generating or transmission and distribution facilities. Measures that moderate the peak demand or control the growth of electrical demand growth can extend the time before additional facilities are needed. The range of options available to a utility is wide and varied. For the purpose of developing a methodology, concentrate on three well understood options available to winter peaking utilities. Summer peaking utilities face the same problem, but would consider different options.

All load control options have two potential effects on the load shape of the controlled end-use. The first is to lower and/or shift the peak demand. This effect allows the peak capacity of the utility to be smaller than it would have been without load control. The second effect of some options is an increase in demand during the "payback" period of the control option.

Peak shifting by load management comes about by changing the time that classes of electrical loads are on line. The conservation effect is the result of making this end-use peak non-coincident with other system load peaks. This is important because it keeps utility revenues from eroding due to load control. In fact, the payback energy is often greater than the energy "lat would have been expended in the equivalent uncontrolled load. As a result, the load factor of a system with load control is higher, and the system has higher revenues and efficiencies. The West German experience has shown that system load factors over $90 \%$ are possible; and United Power of Elk River, Minnesota has achieved substations with a winter peak at 11:00 pm through the use of load management. More modest goals would still be advantageous for most American utilities.

Interruptable load management strategies come in two forms, one is an automatic or timed management strategy and the other is the use of dispatchable load controls. Timed strategies are based on appliances turning off and on at pre-specified times. Examples are water heaters with timers, or ceramic heaters which charge overnight. The advantage of these is that there does not need to be the substantial investment in the dispatching and receiving equipment that dispatchable control requires. Another feature from the point 
of view of market penetration is that a customer knows exactly what the app " iance will do and can plan accordingly. Dispatchable control, in contrast, requires a communication medium, transmitter, and a receiver. Communication media may be radio, telephone, CATV, or a power line carrier. Dispatchable options give the utility the option to choose when and for low long appliances will be turned off. From a utilities perspective, this allows precise micromanagement of some system loads. From the customer's point of view, however, there remains considerable concern about loss of control to the utility and possible inconveniences in the availability of appliances that may result.

Noninterruptable conservation measures are also available. These measures function all the time. A common example is household insulation, another is. downsizing furnaces. These measures do not impose any loss of customer control. Typically they reduce energy as well as peak demand.

\subsection{SELECTION OF OPTIONS}

The feasible set of load management options is dependent upon which seison the system peak occurs. A utility with a sumner peak will need to consider load management options such as air conditioning cycling. Winter peaking ut:ilities receive peak reduction and total load reduction from space heating corltrol, dual-fuel systems, water heating control, or storage heating units. Some options are useful for utilities in either situation. The most versat-le example is the programmable control panel. This panel allows a consumer to control any desired loads.

Since the study area is a winter peaking utility, this study concentrates on winter peaking options. Determinants of success of a program include the: cost of the unit, the maintenance costs, the program cost, and the degree of utility incentives to consumers.

Five load management options are discussed in some detail below. These: options are water heater cycling, space heat rycling, thermal storage heaters, commercial lighting retrofit, and smart programnable panels. These five, although not inclusive of all possible options, represent a practical set that is amenable to modeling. Actual experience in the implementation of 
direct load control options in the BPA region is limited. Because of this, much of the data is drawn from around the country, and to a limited extent, Canadian experience.

Water heating cycling represents one of the earliest methods of load control. From a utility's point of view, control of water heaters provides an ideal option. Water heaters use a large amount of electricity with high peaks. These peaks usually occur after people leave for work in the morning and last for about 2 hours. There are fewer people home at these times, therefore delaying the total reheating of the water poses no burden on the customer. Another feature of water heaters is that shaving the peak does not effect the total amount of electricity needed to heat a given amount of water. The end result is that the peak capacity requirements of the utility are lowered while sales are maintained.

Another form of residential load control is cycling space heating. This provides benefits to the utility in the form of lowered peak demand. This form of load control can often cause hardship for the consumer if not carefully implemented. Quite simply, if the heater is cycled too often, the house gets cold. Consumers are generally reluctant to accept external control of their space heating equipment.

An alternative method of controlling space heating is by thermal storage heaters. The technology of thermal storage units has changed greatly in recent years. Thermal storage devices containing crushed rock are now available, and can keep a room comfortably warm all day from one overnight charge. These heaters provide a steady, clean, and odorless source of heat. As a result, they have advantages for both the consumer and the utility.

A potentially useful form of comercial control is in the area of commercial lighting. Retrofitting conmercial establishments with bulbs of lower energy use can result in a substantial reduction in the total energy demand. Shifting the base amounts demanded by commercial establishment downward helps lower peak demands.

Smart programmable controller panels are another alternative which are attracting growing interest. These panels automatically turn appliances off and on to keep the whole house demand under less than a pre-selected level. 
The great virtue of these panels is that they allow the consumer to pick the order in which appliances may be turned of $f$ and explicitly relate electrical demand levels to personal choices in comfort and convenience.

System peaks are as much a function of coincidence in the timing of individual peaks as they are functions of total electricity demand. The best load control program for a given utility will depend on the load curve shape contributed by various customer classes and the saturation of the different appliances that are amenable to load control. 


\subsection{TOLEDO-WREN CASE STUDY}

The Toledo-Wren case was selected as the subject of this study to facilitate the development of a CILOC methodology as discussed in Section 1.0. With this orientation of the study, the area chosen needed to satisfy the following diverse criteria:

- representative utilities

- a cooperative BPA - utility atmosphere

- a previously studied construction alternative

- a simple construction alternative

- enough data on hand to ensure accurate results.

The Toledo-Wren $230 \mathrm{KV}$ line construction project proposed in the 1985 Ten-year Plan Facility Construction fit these requirements closely.

The proposed construction project involved two Western Oregon utilities, Central Lincoln PUD and Consumer's Power Corp. While both cooperate with BPA and take interest in BPA-sponsored research, they have markedly contrasting styles in management and attitudes towards data analysis. Central Lincoln routinely takes a very active role in gathering a variety of information about their customer base. Efforts include appliance saturation surveys, metering experiment: for both commercial and residential classes, an active homeowner audit program, and a sophisticated computer support program to make this information available quickly and accurately. Consumer's Power generally takes a much less intrusive approach to monitoring their customer's activities. They have obtained a saturation survey of household appliances and maintained a file of homeowner audits. There are significant differences in the type of data available from the two utilities. This situation can be expected whenever more than one utility's service area is encompassed by a case study of this type.

While the energization plan for the Toledo-Wren $230 \mathrm{KV}$ line reinforcement was 1989, recent revisions of BPA's prior forecast have pushed the need date out past 1995. The use of this case should therefore be relatively noncontroversial. If this pilot case study had been undertaken on an imminent construction project, technical considerations might not have been easy to separate from institutional issues. 
The Toledo-Wren case also represented an opportunity to rely upon a corstruction study which had already been completed. By using the engineering and costing data which had been gathered, the pilot case study could be performed with fewer resources than if a site had been chosen at random.

Another feature of the Toledo-Wren reinforcement which made it attractive was its relative simplicity. The construction plan is for a single line feeding only two utilities. This allowed the study area to be clearly defined. By restricting the study to a well-defined area, data gathering efforts were more easily focused.

A final advantage is the study area's proximity to an end-use metering experiment. During 1983 Pacific Power and Light undertook an end-use metering experiment which involved individually-monitored space heating and water heating. Other end-uses were measured as a residual. Houses were metered in Bend and Albany, Oregon. Since Albany is close to the Toledo-wren study area, the PP\&L metering experiment provides end-use load curves which are critical in estimating the effect of conservation impacts of the load control options considered.

In the following section data used for the case study is summarized, arid the required modifications explaining. A listing of data sources for the case study is provideu in Appendix A.

\subsection{END USE LOAD CURVES}

The basis for the analys is is the end-use load curves. Since the AlbaryBend metering experiment provided the residential end-use load data, the encuses considered (Figures 5.1 through 5.3) were restricted to water heater, space heater, and other uses (a residual). Figure 5.4 shows the total residential sector load shape. Commercial end-use curves were taken from Seattle City Light metering experiments. The industrial shape was constructed based load factor and work shift information provided by Central Lincoln PUD.

The following sections summarize the data that support the development of the load shapes used for the residential sector of the analysis. 


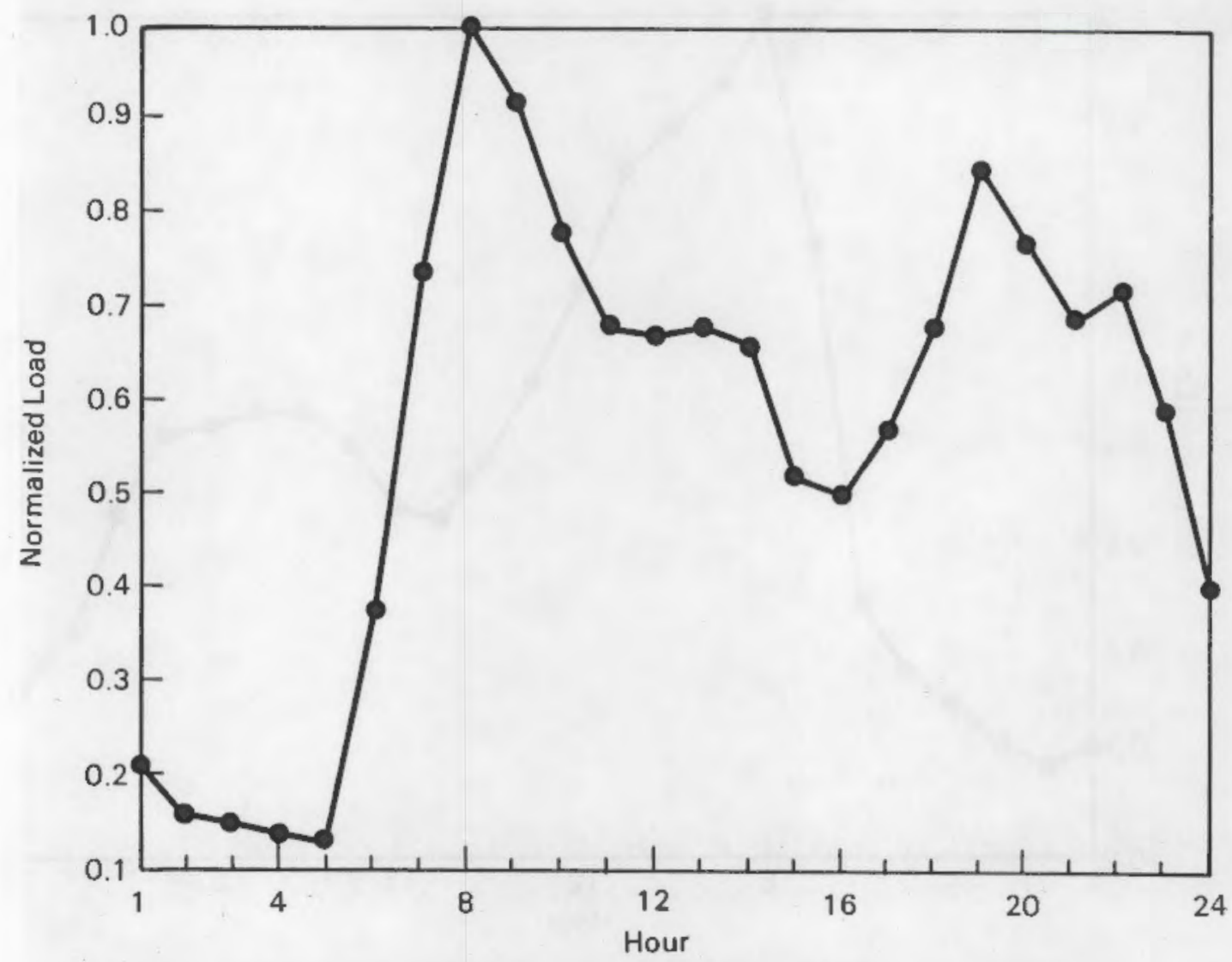

FIGURE 5.1. Normalized Water Heat Residential Load Curve

\subsection{NUMBER OF RESIDENTIAL ACCOUNTS}

Consumers Power - Telephone contact with Consumers Power revealed that they had 5455 residential accounts, as of January 1985. It was also reported that this figure overstates the number of residential accounts by $5 \%$. The adjusted number of residential accounts is therefore $5182(0.95 \times 5455)$. It was assumed that this corresponds to the number of residential accounts at the end of 1984. The next step was to allocate these accounts among the following three dwelling type categories: 1) nonmobile home constructed prior to 1975 ; 2) nonmobile home constructed in 1975 or later; and 3) mobile home. This step is recorded below: 


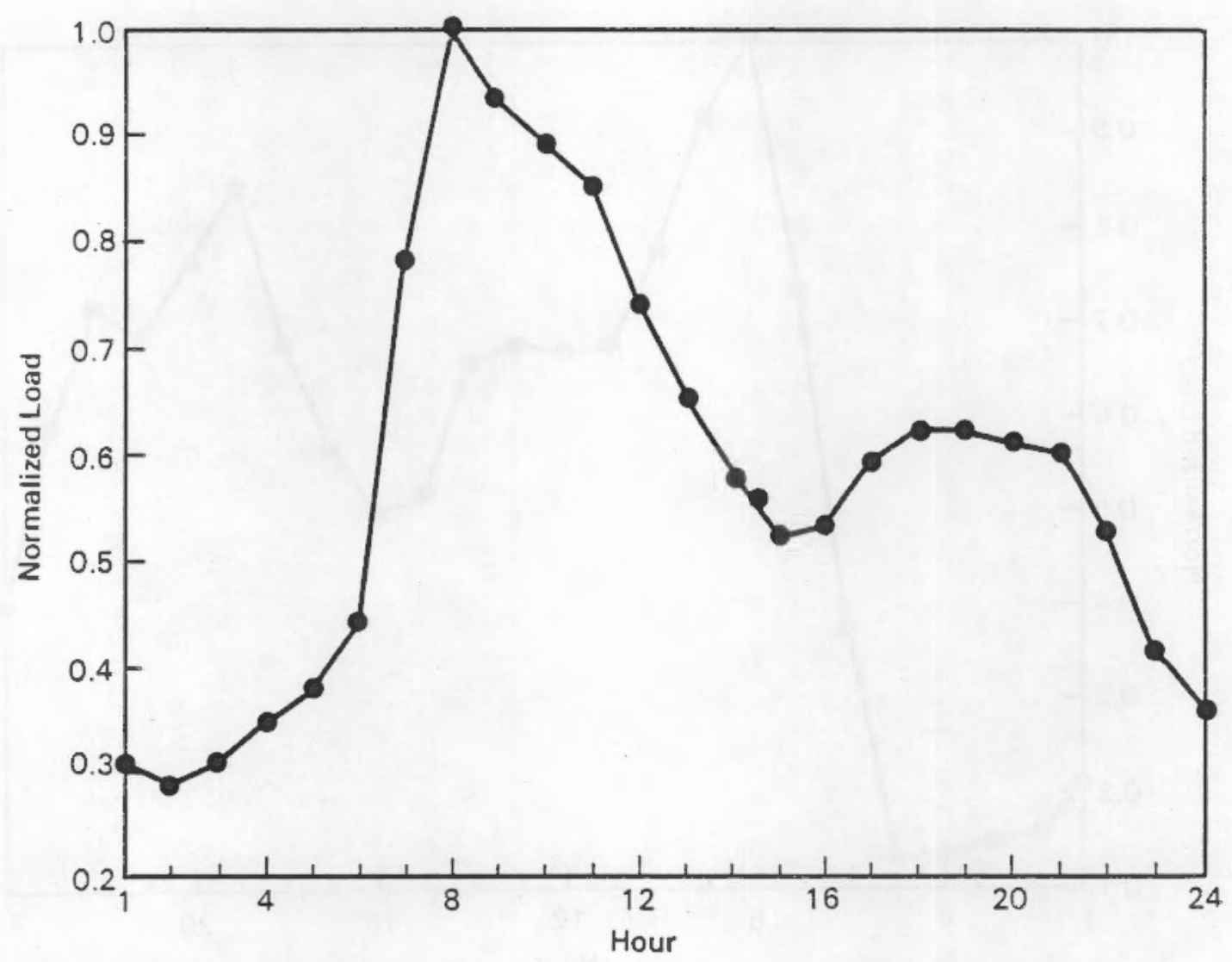

FIGURE 5.2. Normalized Space Heat Residential Load Curve

New Accounts (1981-1984): $4 \times 173=692$

173 new accounts

in 1984; same

number as sumed

for 1981 through

1983.

Nonmobile homes: $0.468 \times 692=324$

$53.2 \%$ of new accounts in 1984 were for mobile homes.

Mobi ?e homes: $0.532 \times 692=368$ 


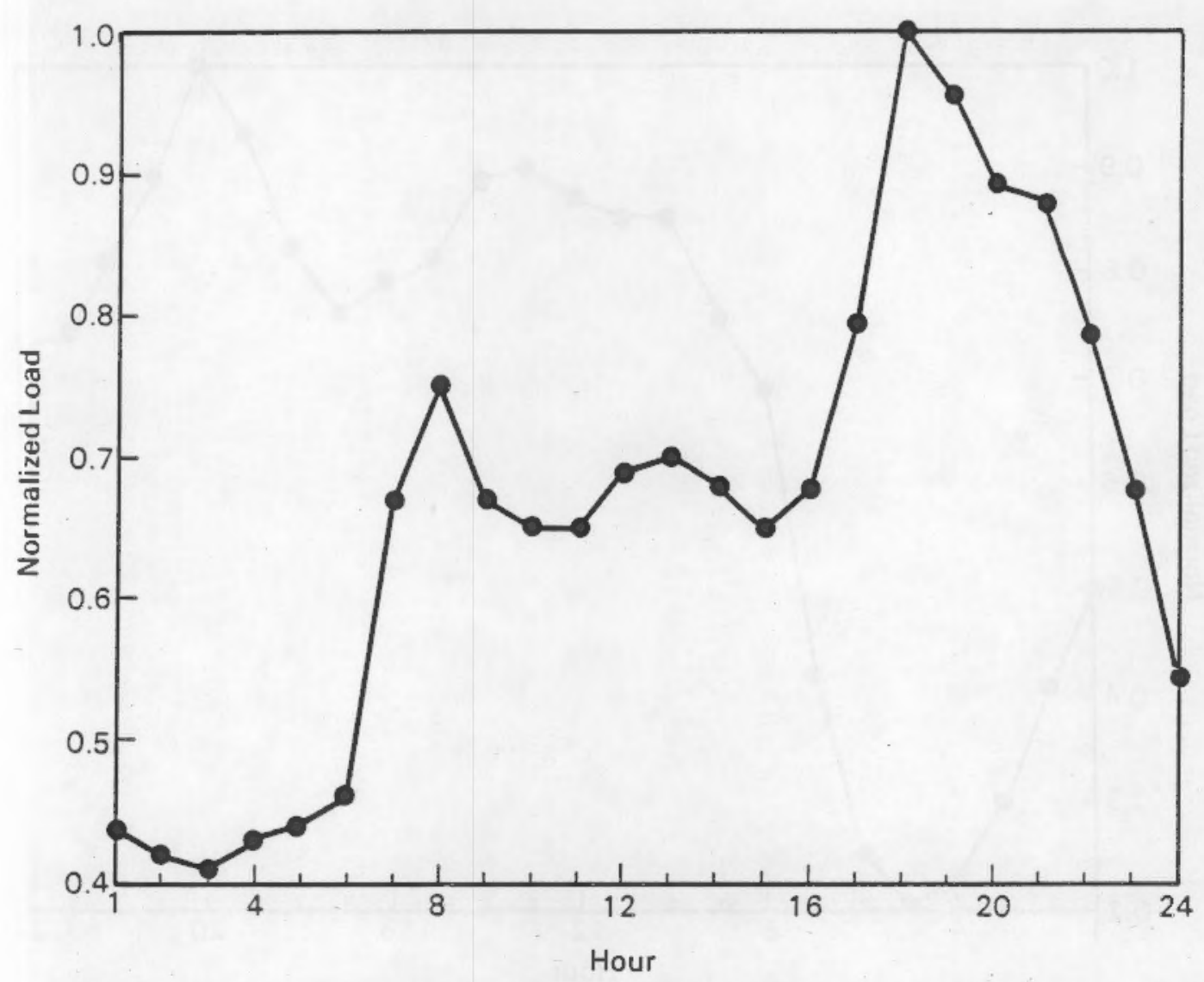

FIGURE 5.3. Normalized Other Uses Residential Load Curve

1980 Stock: $5182-692=4490$

Nonmobile homes: $0.822 \times 4490=3691 \quad 17.8 \%$ of the 1980 accounts were mobile homes.

Mobile homes: $0.178 \times 4490=799$

1984 Stock: 5182 accounts

Nonmobile homes: $3691+324=4015$

Mobile homes: $799+368=1167$ 


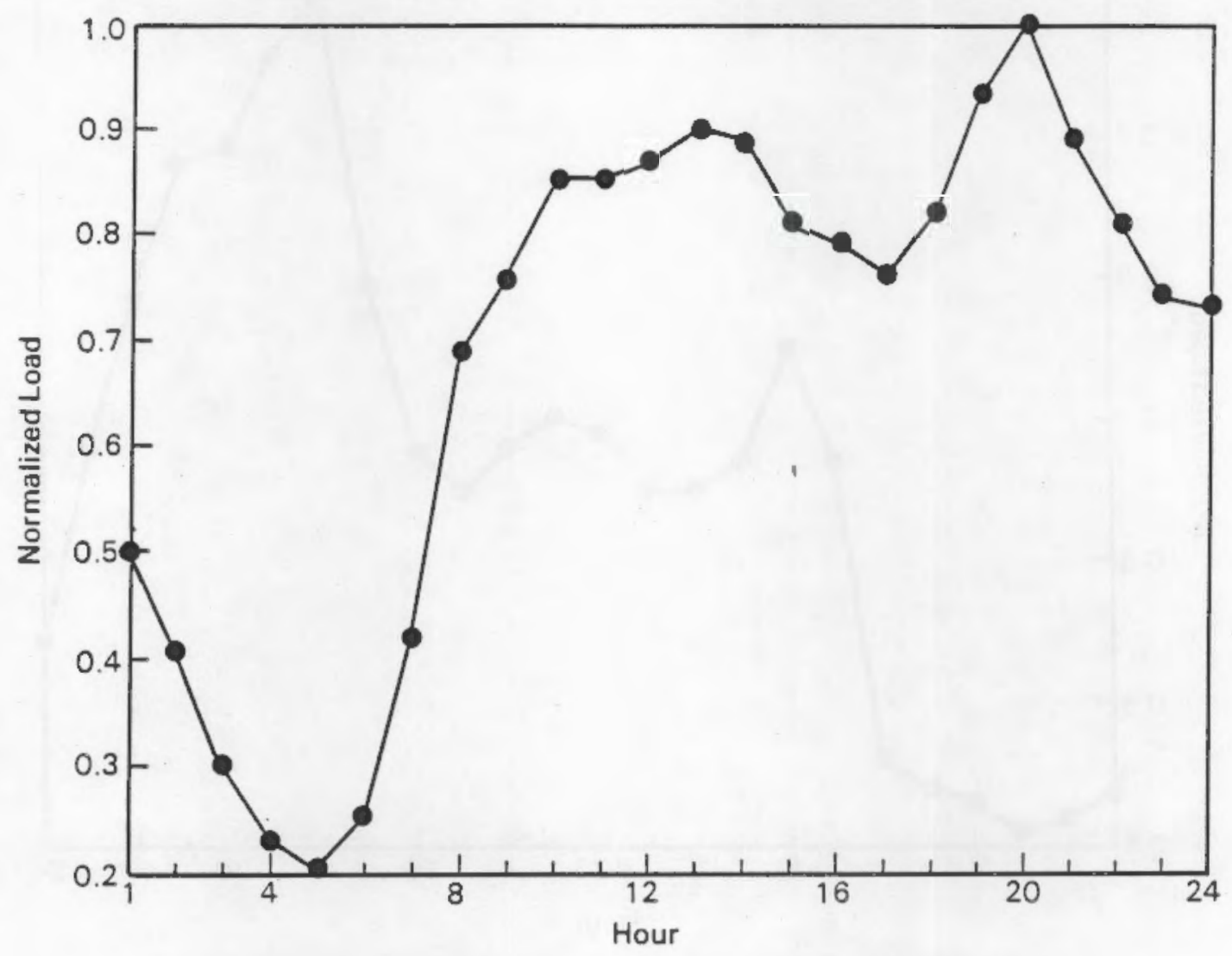

FIGURE 5.4. Normalized Total Residential Load Curve

Central Lincoln - The following information was obtained from a SAS file:

1984 Stock - Residential Accounts: 11,381

Nonmobile homes: 8,991

Mobile homes: 2,390

\section{Total Study Area}

1984 Stock - Residential Accounts: 16,563

Nonmobile homes: $4,015+8,991=13,006$

According to the 1980 Census, the number of houses in Lincoln County built in 1970 or later was 7,816. This represents a $4.9 \%$ annual growth rate between 1970 and 1980 . The comparable growth rate for Polk County was $5.1 \%$. Therefore, for the 
study area, a growth of 5\% in the housing stock between 1975

and 1984 was assumed. This gives the following breakdown:

Pre-1975 nonmobile homes: $\quad 10,169$

1975 \& later nonmobile homes: 2,837

Mobile homes: $1,167+2,390=3,557$

\section{Customer Forecast}

Assumed loss in pre-1975 nonmobile home stock of $1 \%$ per year, and assumed net increase in total stock of $1.50 \%$ per year basis.

$0.0150 \times 16,563=257$ additional units per year, net. Number of lost units (assumed all pre-1975) is $.01 \times 10,169=102$.

Total number of additional units is $257+102=359$.

Number of nonmobile homes: $0.468 \times 359=168$

Number of mobile homes: $\quad 0.532 \times 359=191$

Implied annual rate of growth of housing stock is:

Nonmobile, old $\quad-1.0 \%$

Nonmobile, new $168 / 2837=5.9 \%$

Mobile homes $191 / 3557=5.4 \%$

Loads and load forecasts by customer class for utilities in the study area are provided below. Loads and load forecasts are added across utilities to provide totals for the study area. Winter load curves are required for residential water heating for both base case and conservation case. Winter load curves are required for commercial lighting for both base case and conservation case.

The peak month is in 0ecember. This was determined as follows: from BPA Form 980, the forecast peak demands for December and January were identified for the Toledo point of delivery (POD) of Central Lincoln, and the Toledo and Wren PODs for Consumers Power. The peak demands were combined over PODs for December and January. The December peak was higher than the January peak for all forecast years. 
System peak hour and residential class peak hour are at 8:00 am.

Appliance saturations are listed below. These saturations apply to the entire service area of the utilities and may differ somewhat from actual appliance saturations in the study area.

\section{Saturation Rates}

Rates taken for Consumers Power. (See Page A.22, Consumers Power, 1985 Power Requirements Study.)

\begin{tabular}{|c|c|c|c|}
\hline & 1984 & 1989 & 1994 \\
\hline Space Heat & $58.2 \%$ & $61.2 \%$ & $64.2 \%$ \\
\hline Water Heating & $88.7 \%$ & $89.0 \%$ & $89.7 \%$ \\
\hline ther End-Use & $100.0 \%$ & $100.0 \%$ & $100.0 \%$ \\
\hline
\end{tabular}

Saturation series selected to fit each set of 3 data points above. For space heat, series starts at $53.0 \%$ for 1976 and ends with $67.2 \%$ for 1999 .

For water heating, series starts at $88.0 \%$ for 1976 and ends with $90.0 \%$ for 1999 .

For other end use, series is constant at $100.0 \%$.

Assumed average annual kilowatt hour usage for existing and replacement appliance stock are shown below.

\section{Average Energy Usage}

\begin{tabular}{|c|c|c|c|}
\hline & 1984 & 1989 & 1994 \\
\hline Space Heat & $7000 \mathrm{kwh}$ & $6060 \mathrm{kwh}$ & $5560 \mathrm{kwh}$ \\
\hline Water Heating & 3500 & 3400 & 3300 \\
\hline her End-Use & 6836 & 6916 & 7002 \\
\hline
\end{tabular}

Source: Consumers Power, 1985 Power Requirements Study (see Appendix A, page A.22). 
Energy usage for the three dwelling types was selected to fit 1984 value.

Average 1984 usages are as follows:

Space Heat (Average per unit from PRS is $7000 \mathrm{kwh}$ )

Nonmobile, old $8500 \mathrm{kwh}$

Nonmobile, new 5500

Mobile homes $\quad 4000$

Weighted average $=7020 \mathrm{kwh}$ (weights proportional to number of 1984 units)

Water Heating (Average per unit from PRS is $3500 \mathrm{kwh}$ )

Nonmobile, old 3650 kwh

Nonmobile, new 3550

Mobile homes $\quad 3000$

Weighted average $=3494 \mathrm{kwh}$ (weights proportional to number of 1984 units)

Other End-Use (Average per unit from PRS is $6836 \mathrm{kwh}$ )

Nonmobile, old $7200 \mathrm{kwh}$

Nonmobile, new 6900

Mobile homes $\quad 5750$

Weighted average $=6838 \mathrm{kwh}$ (weights proportional to number of 1984 units)

Weather normalization was necessary for the purpose of adapting residential metered Bend-Albany data for purposes of the study in Lincoln County, Oregon and environs. Weather data were obtained for Newport, Oregon; Corvall is, Oregon; Redmond, Oregon; and Salem, Oregon, as indicated in Appendix A. Most of the data are hourly surface weather observations from 1977 through 1985; most digitized; long-term summaries were also obtained. 
Appliance Lifetime

Appliance lifetimes are assumed as follows:

$$
\begin{array}{ll}
\text { Space heater, nonmobile home: } & 25 \text { years } \\
\text { Space heater, mobile home: } & 20 \text { years } \\
\text { Water heater, all dwelling units: } & 15 \text { years }
\end{array}
$$

Cost/benefit analysis compares the costs of implementing some average direct control program that delay transmission construction with the benefits of delaying construction. Costs of implementation include the hardware costs, the maintenance/administrative costs, and any incentive payments to the consumer. The benefits are the alternative uses of the funds otherwise committed to the construction project. While the costs and benefits clearly move together, this analysis will not focus on analyzing the optimal direct control progran. Rather "average" programs will be postulated and the net benefits of these programs are calculated. Using average programs as the base keeps the analysis focused on methodology and generally reasonable results. In the following, cost/benefit analysis will be performed across several cases on a case-bycase basis. Each scenario is briefly described and then analyzed.

Weathe information also plays an important role. Microcast requires a peak day adjustment figure. This figure is a percentage above average. In this analysis, a peak day was assumed to be $70 \%$ higher than an average day.

\subsection{RESULTS}

Several problems with the commercially available software were revealed during the course of the study. These difficulties may be primarily attributed to unique requirements of assessing strategic conservation. Assessment of strategic conservation requires that the target end use and/or population be separated from the rest of the system load. Careful assessments of their behavior and responses to conservation programs need to be individually identified. As will be discussed, these requirements are more rigorous than those more general conservation assessment software packages need to meet. The result of these problems was that direct application of the software packages was not acceptable. 
The approach taken was to combine the virtues of the two packages with some simple programming changes and manipulations to forecast the effect of conservation on system peak in the Toledo-Wren area. The procedure followed in this study is outlined below.

Initial work concentrated on developing a base case. This effort essentially consisted of reproducing the 1982 BPA forecast using Microcast. No conservation measures were assumed to be implemented and the system load shape between 1984 and 1999 was forecasted. Since there is no conservation action going on during this time, the inability to differentiate between conservation and improvements in the replacement stock of appliances was inconsequential. The base case formed the basis for all the subsequent cases.

Each of the residential conservation cases were forecast using Loadcalc. The technique was to simulate Loadcalc 24 times for each scenario. This was done to overcome the problem of Loadcalc operating under the assumption that peak hour did not change due to the conservation. By filtering through each of the 24 hours in a day, the results of Loadcalc could be used to estimate the new, controlled, end-use contribution to system demand. System load shapes were found by subtracting the uncontrolled end-use contribution and adding back the controlled shape. Figure 5.5 shows the total system load under each of the regimes.

\subsubsection{Base Case Scenario}

The base case is a system load curve forecast for the period from 1984 to 1999. These system load curves were based, as much as was possible, on the BPA 1982 forecasts. In our forecast, system peaks occur at 8:00 am throughout the forecasted period. The 1990 peak is 223 megawatts. Since all the scenarios are based on the same data and forecasting techniques, the comparisons are internally consistent.

\subsubsection{Water Heater Control}

The first control scenario is the implementation of a water heater control program. This program is one which offers a $\$ 50$ incentive to the consumer and is based on hardware which costs $\$ 75$ per installation. The control meter is to shut off water heaters at 8:00 am and 9:00 am, control them at lower 


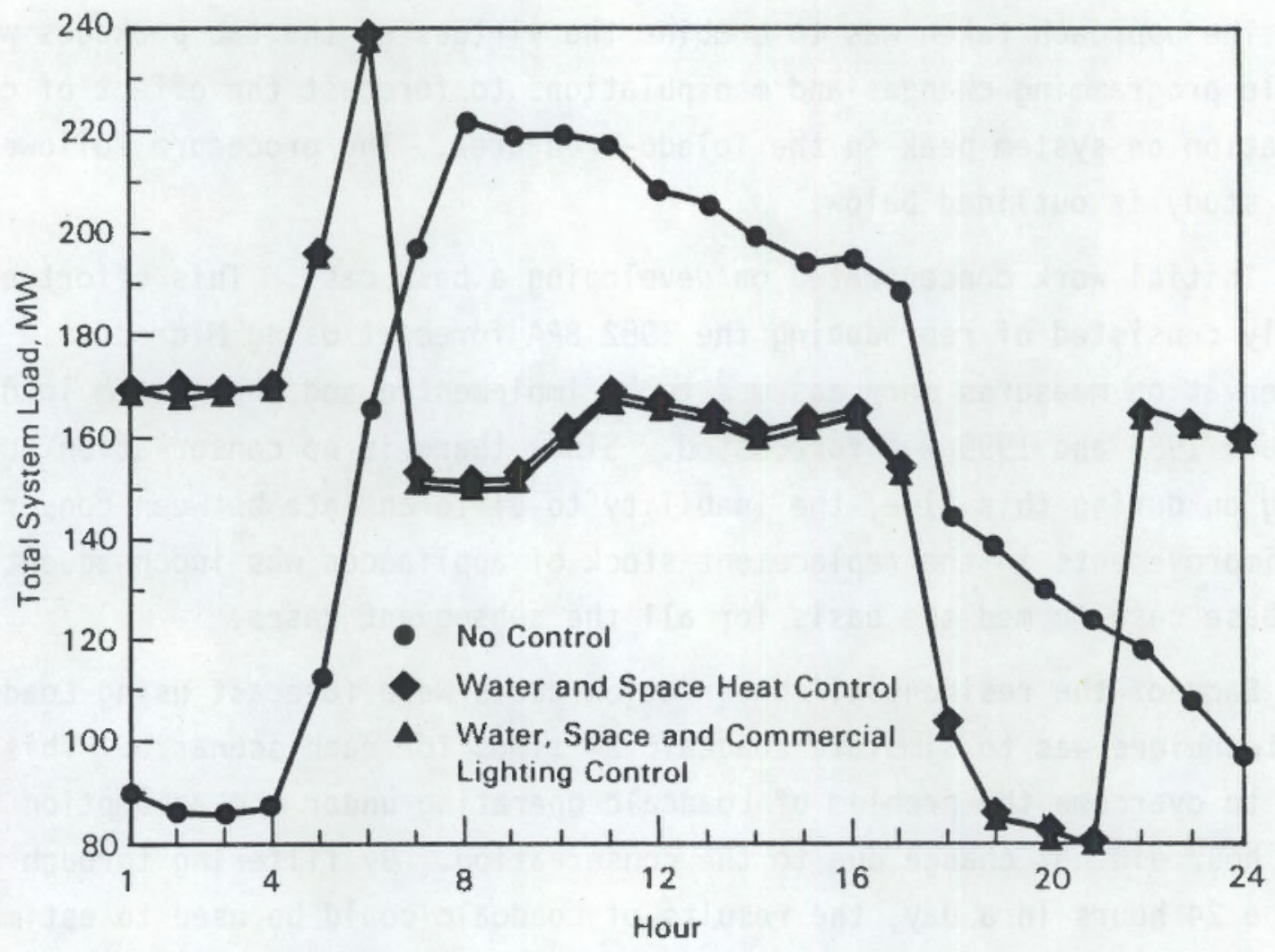

FIGURE 5.5. Total System Load Curve

levels of use until 12:00 pm, and allow payback at 1:00 pm and 2:00 pm. Figure 5.6 shows the residential sector controlled and uncontrolled hourly loads. Penetration is presumed to be fairly rapid with $17 \%$ signed up in the first year, $27 \%$ in the second, and $35 \%$ in the third. The ultimate target is $80 \%$. This program would delay the occurrence of 223 Megawatt system load which triggers new construction by 1.03 years (1991). The 1990 peak reduction is 6.11 megawatts and peak is shifted from 8:00 am until 10:00 am. With $17.5 \%$ penetration, in 1.03 years the costs are $17.3 \% \times 16,755 \times(\$ 75+\$ 50)=\$ 371,125$. Benefits are calculated as the alternative return the investment could have gathered. Since the project is put off 1.03 years, the benefit to implementation is $\$ 460,000$. The net benefit is $\$ 88,875$.

\subsubsection{Ceramic Room Heater Program}

The space heater control scenario is based on implementation of ceramic room heaters. While it is technically possible to cycle space heating in the same way as water heating, there has been a great deal of resistance on the 


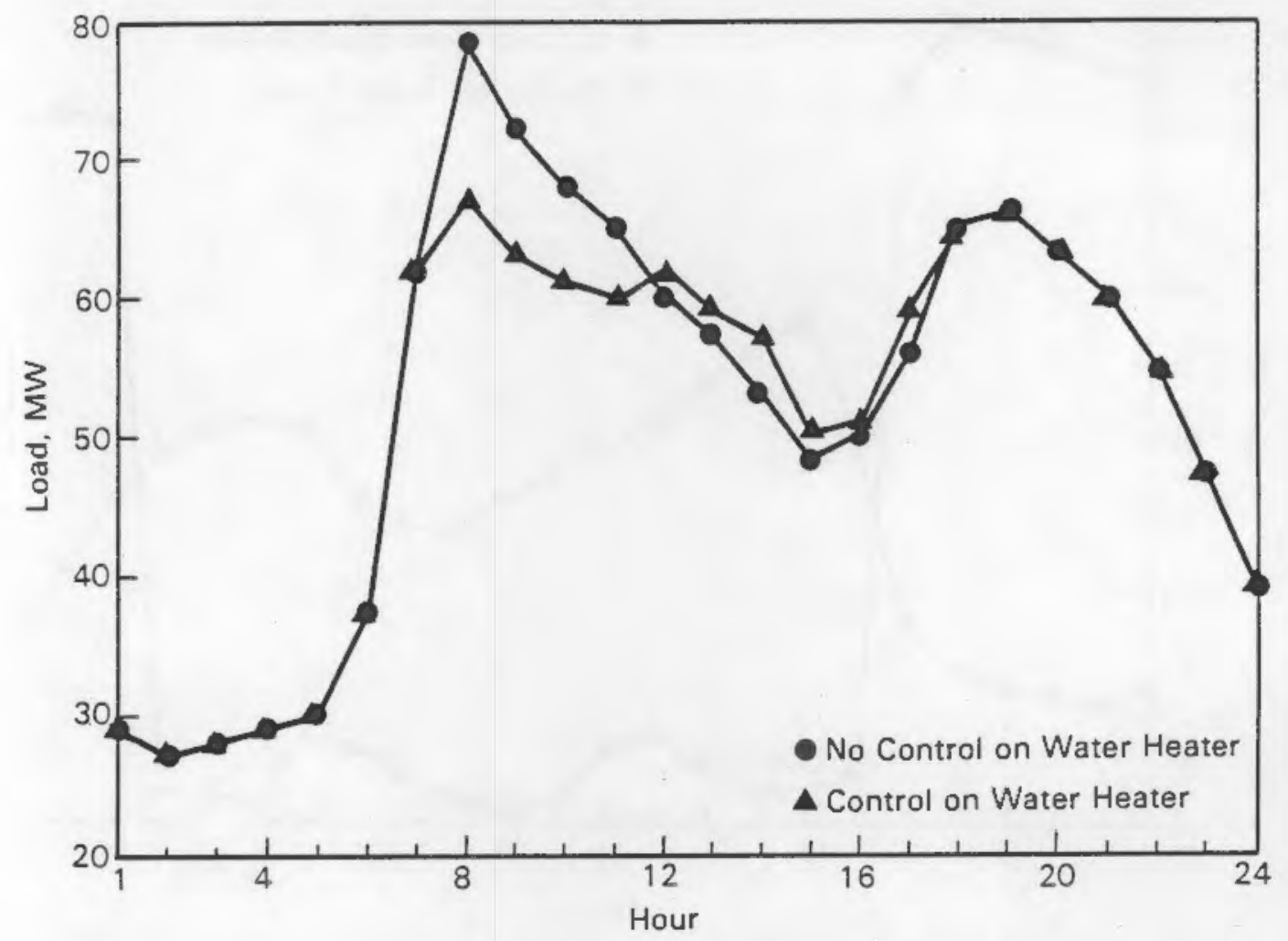

FIGURE 5.6. 1990 Residential Sector Water Heater Load Curve

part of consumers to participate in these kinds of programs. The study area is also an area where much of the space heating is used to supplement other types of heating. This makes room heaters more attractive to consumers. Ceramic heaters are more expensive, but seem to be much more acceptable to consumers. The schedule of customer acceptance assumed in this study is to have $5 \%$ in the first year, $10 \%$ the second year, $20 \%$ the third year, and $25 \%$ the fourth year. Market prices for ceramic room heaters appear to be around $\$ 500$ per heater. The program assumption is to simply buy the heaters for any interested consumer. This program delays the 223 Megawatt peak for 2.46 years. Figure 5.7 shows the residential sector load profile. Penetration of heaters in 2.46 years is $12.3 \%$ of the population. This implies that the cost of the program will be $12.3 \% \times 16,755 \times \$ 500=\$ 1,030,433$. The benefit of delaying the construction of the system is $\$ 1,150,000$. The net benefit is about $\$ 120,000$. 


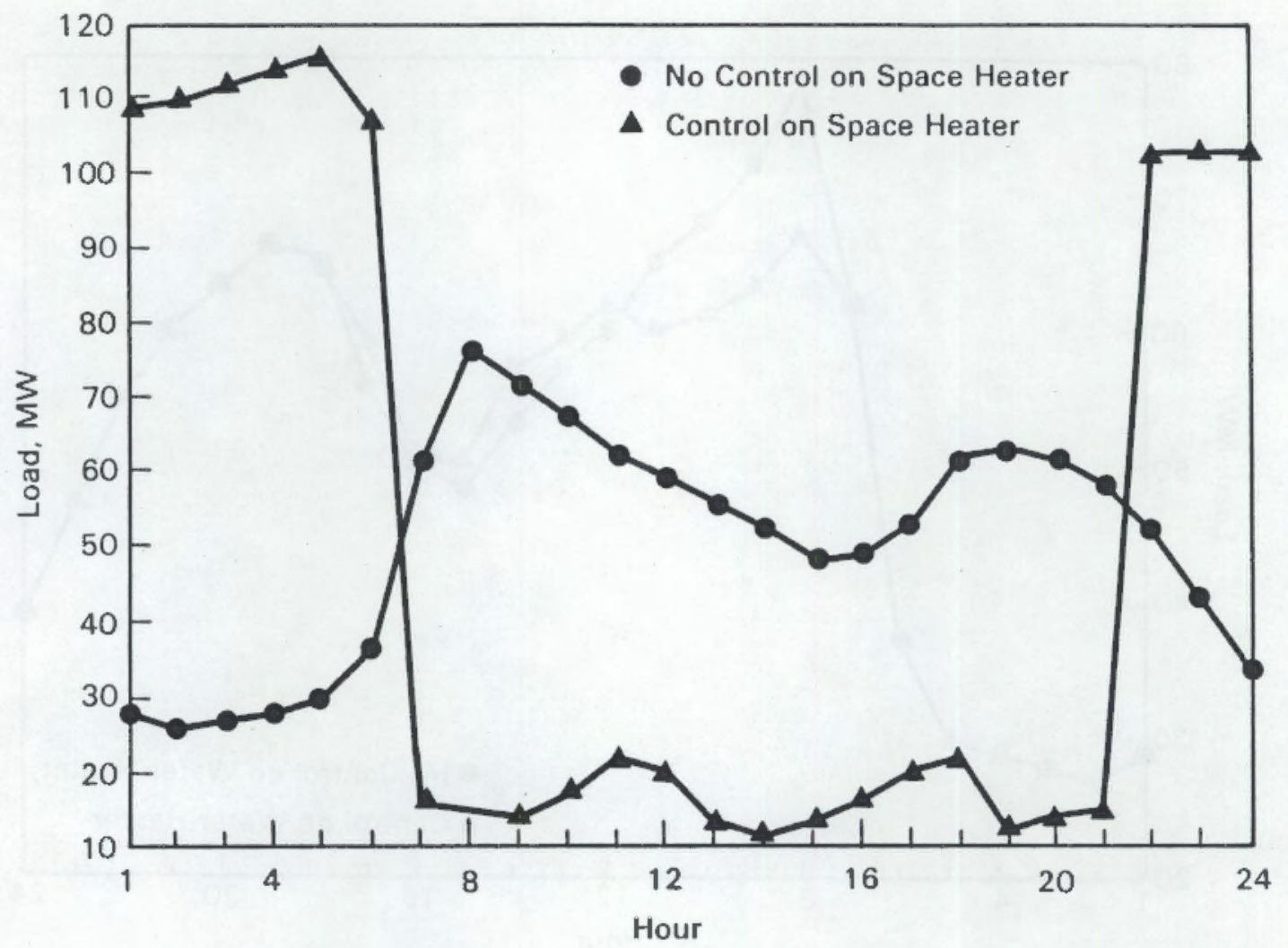

FIGURE 5.7. 1990 Residential Sector Space Heater Load Curve

\subsubsection{Combined Program: Water Heater and Space Heater Control}

The final program considered here is a program which includes both water heater control and purchase of ceramic heaters. We assume that the penetrations of both water heater controls and ceramic heaters will be at the same rate as the cases above. A combined program delays the proposed construction 3.33 years. The drop in the 1990 peak demand is 19.3 Megawatts. This is slightly less than the total of the two individual programs. Cost of this program is in two components. Water heater control cost is $37.5 \% \times 16,755 \times$ $\$ 125=\$ 785,390$. Ceramic heater cost is $16.65 \% \times 16,755 \times \$ 500=\$ 1,394,854$. The total cost of the program is estimated to be $\$ 2,180,244$. Benefits of delaying the project 3.33 ycars are $\$ 1,590,000$. The net benefit is $-\$ 590,000$. This result suggests that a program like this delays the construction too long. 


\subsubsection{Cormercial Lighting Program}

Another program which was considered was a high efficiency lighting retrofit program for commercial lighting. Figure 5.8 shows the commercial sector load profile with and without the lighting program. The commercial lighting program does not delay the energization date measurably. Forecasted reduction in 1990 peak due to commercial lighting retrofit is less than 2 kilowatts. The delay in construction is less than 60 days. This program is clearly not large enough to justify its implementation on the grounds that it would delay construction of the Toledo-Wren reinforcement line.

\subsection{CONCLUSION}

One undesirable side effect of the current constraints on analysis is that the conservation program appears to move the peak away from 8:00 am to 5:00 am. The conservation programs chosen, in particular, the ceramic space

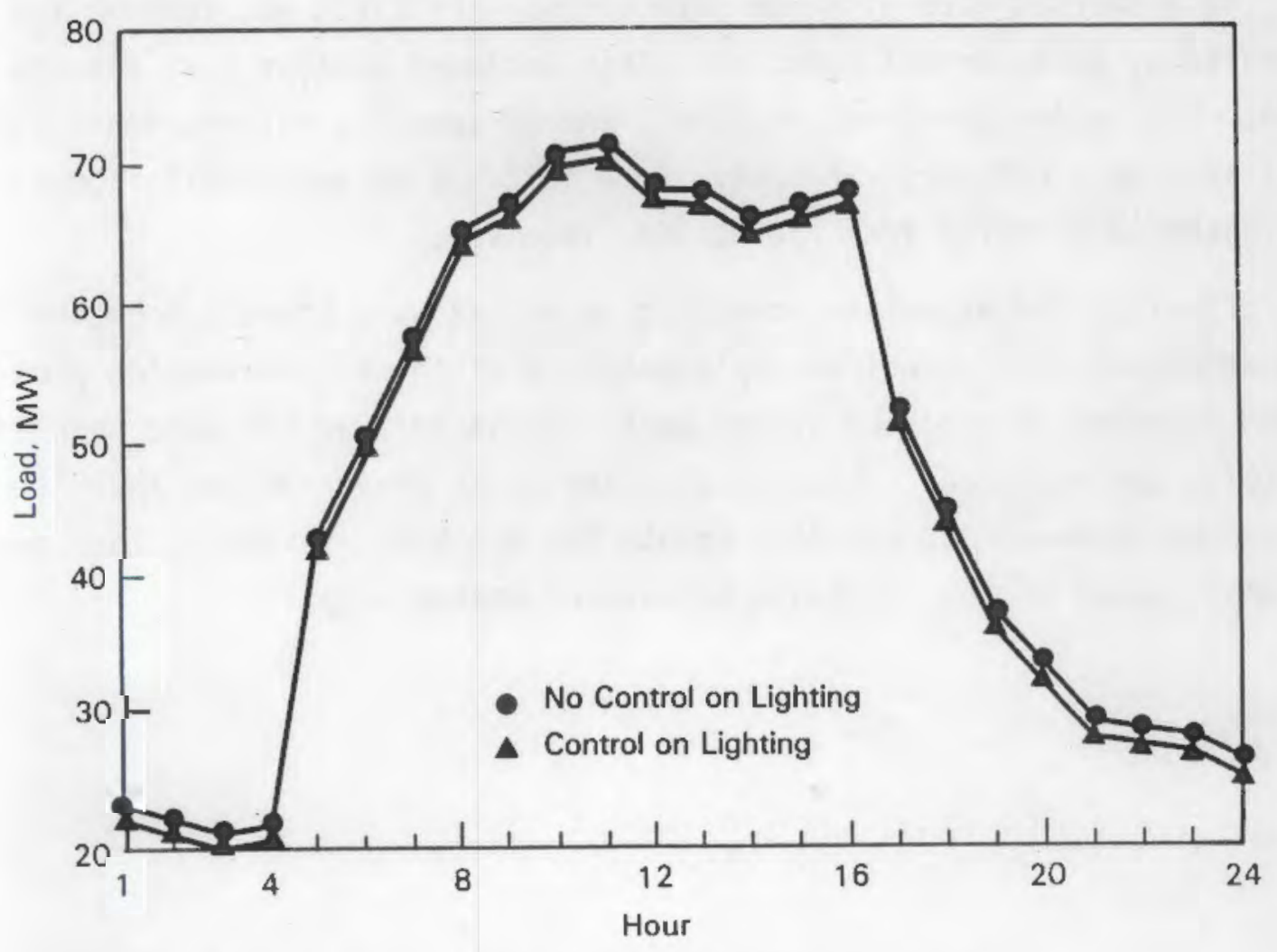

FIGURE 5.8. 1990 Comnercial Sector Load Curve 
heater program, resulted in a peak which was higher than the original peak. This result is a consequence of the timing of the recharging of the ceramic heaters. Simply starting the recharging an hour earlier would have been sufficient to remove the new peak. Unfortunately, the software was not adequately flexible to allow this adjustment to be made at low analytic cost. The expected effect of this recharging scheme on the peak shifting would have been the same as ignoring the new peak. Since removing the 5:00 am artificial peak would not effect the results this case was not rerun, and Figure 5.7 retains the artificial peak. Subsequent development of the software would allow fine tuning to prevent these anomalous results.

Implementation of a conservation program with an eye towards differing a transmission or distribution constraint requires a substantial investment in data collection and analysis. A number of different sources of data needed to be combined to achieve the necessary level of understanding and expertise needed to perform the analysis.

Data sources were of three categories. The first was information routinely gathered by governmental agencies. This included weather data and census data. The second group was regional, energy-specific information. Load shapes fall into this category. Finally, some information was utility specific, and was gathered directly from the utility involved.

Finally, the expertise, modeling, and data were brought together to assess the deferment available from implementation of three conservation programs. These programs delayed the system peak, and so delayed the date when additional capacity was required. These results are point estimates and their sensitivity to various assumptions and data points has not been assessed. They do represent an application of the strategic assessment methodology. 


\subsection{ASSESSMENT OF RESULTS USING COMMERCIAL SOFTWARE}

The case study demonstrated that end-use modeling techniques can be used effectively to evaluate the potential for conservation. An important, although not unexpected, finding was that all residential conservation programs examined delayed the need for additional transmission. Three residential and one commercial load management programs were examined. The simple, illustrative, residential programs delayed T\&D construction from just over 1 year to $31 / 3$ years. The commercial lighting program was less effective, with only a few months delay feasible. This is not surprising since the portion of the system load represented by comnercial lighting is small. These results are more revealing of the work to be done than they are of policy value.

Two pieces of software, Loadcalc and Microcast, (a) were purchased to assist in our evaluation efforts. These are end-use modeling programs which use the LOTUS $123^{\circ}$ (b) operating environment. Microcast was designed to forecast the residential system demand (in the residential module), and commercial system demand (in the commercial module) given a variety of information centering around information about load shapes, end-use saturations, and forecasts about these variables. Loadcalc was designed to estimate the effect of a single

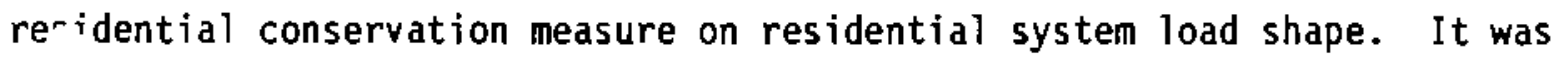
based on the same end-use modeling techniques as Microcast.

Microcast builds a residential system load shape based upon aggregating individual building's end-use load shapes. Microcast has provisions for several end-uses and several different residential types. The difficulty is that the shape associated with an end-use is identical across all residential types. For instance, water heater shapes are assumed identical across mobile homes, apartments, and detached single family dwellings. In a situation where there is not a great diversity in housing types, this assumption may be tractable. This was not the situation in the Toledo-Wren case study. For instance, over $20 \%$ of the residential housing stock is composed of mobile homes. Unfortunately, this assumption is so deeply imbedded in the Microcast software, that its use was unavoidable.

(a) Available commercially from AEG.

(b) LOTUS 123 is a trademark of Lotus Development Corporation. 
Loadcalc was to be used to evaluate the effect of conservation on system shape and peak. The software proved to be too seriously flawed in applications such as the Toledo-Wren case study to be of much use. One aspect of Loadcalc which was problematic was its inability to differentiate lowered future demand for electricity due to conservation from that which resulted from the increased efficiencies of replacement stocks. This confusion between the effect of conservation and the effects of natural replacement of worn out stock is no: a problem if simple forecasts are all that are needed. However, this study was interested in evaluating the effect of a deliberate policy of encouraging conservation. The inability to assign lessened peak or total demand to either natural forces or the policy makes evaluation impossible.

Another more serious problem was in the calculation of peak system sav ngs due to conservation. Loadcalc assumed that the peak hour would not change due to conservation. This was clearly inappropriate for the Toledo-Wren case study. The load management programs being investigated in this study are capable of moving as well as lowering system peak. There was no reason to assume that the results given by Loadcalc relate to the actual events impli is by the input information.

As a consequence of these problems, a considerable amount of custom ta $i$ loring was requ.red to examine each individual conservation option. Three general problems lay in the approach adopted in Section 5.0 to overcone these constraints. First, there remained a considerable level of analyst input time required to manipulate the data. Second, the manipulations were difficult to follow when verifying the results. Finally, several important analytica. features were impossible to incorporate into the analysis as it was described in Section 5.0 .

The experience gained with the use of commercially-available software and the demonstrated overall viability of the methodology were motivations for the software developments described in Section 7.0. 


\subsection{SOFTWARE DEVELOPMENT}

The substantial difficulties associated with the use of the commercially available software to analyze strategic conservation options were outlined in Section 6.0. As a result of these difficulties, a new software package was developed for use in this project. This software was used to address the problems and needs of assessing the effect of conservation programs on the energy load growth experienced by individual utilities. The new software was developed to provide a quick, tractable tool for use in analyzing conservation programs.

\subsection{SOFTWARE REQUIREMENTS AND DEVELOPMENT}

The focus of the new software development was to enhance the ability of the analyst to perform CILOC assessments using the basic methodology developed in this study. An important consideration was to keep the software within the realm of fairly standard personal computers. Therefore, two hardware requirements were designed into the specifications of the software. One was that it operate with the DOS operating environment. A second was that it operate on current off-the-sheif personal computers. The second objective was essentially that the software be compatii $@$ with either an IBM compatible personal computer (PC) with expansion to 1 MB of RAM, or a standard IBM PS/2 PC.

The software package which was developed is centered around the JAVELINO(a) operating system. JAVELINO is a time series modeling package which operates in the DOS environment. There are several attractive features to JAVELIN' which made it an outstanding candidate for this application. One is that it contains internal knowledge of time relationships. The relationships between days, weeks, and years etc. are imbedded in the JAVELINO software. This makes aggregation or disaggregation of time series variables straightforward. A second attractive feature is its preprogramed graphic capabilities. These two features are very important when working with load shapes. Yet another feature was JAVELIN's@ ability to self document the models it contains. The

(a) JAVELIN is a trademark of Javelin Software Corporation. 
relationships between variables is clearly laid out in tree diagrams. Self.. documentation allows the analyst enormous freedom to edit the models in respionse to the particular circumstances of the problem under consideration. Taken as a whole, JAVELIN@ provided the best available operating environment availab"? for the development of this software tool.

Conceptually, a prime objective of the development process was to create a tool that was composed of interconnected modules. Compartmentalizing the modeling functions allows quick and easy changes for sensitivity analysis. This also encourages building module libraries. Once a library of modules tas been built, custom analyses are much easier to perform.

Another objective of the modeling effort was to create software that could operate at either the system- or the customer-class level of aggregation. Some analyses, for example, might be aggregated to the residential customerclass level. Others would be aggregated all the way to the system level. The absence of this capability was a particular weakness of the commerciallyavailable software discussed earlier in this report.

The new software package was programmed in three basic templates:

- Load-Shape Module

- End-Use Module

- Summary Module.

These three templates can be replicated in a variety of ways to fit the requirements of many analyses. Their functions are described below.

\subsubsection{Load-Shape Module}

The load-shape module is the simplest of the three module templates. This module is designed to contain the load shape of a single end use. This load shape shows the hourly electrical demand of the end use. Load shapes can be constructed for a various degrees of aggregation. In general, two levels of detail seem to be prevalent in applied studies. The first is to measure total hourly loads at the building level. A second, more detailed level is to develop hourly load shapes at the appliance level. Either approach can be accommodated in the load-shape module.

Once the level of aggregation for the load shape has been decided, the time period of interest must be chosen. The load-shape module allows each 
month over a 20-year time period to have the same or a different load shape. Most studies will maintain the assumption that, while the shapes change over seasons, they are stable of over years. Any combination of shapes can be handled easily.

\subsubsection{End-Use Module}

The end-use module contains the information about buildings that exhibit a particular end-use load shape. This information includes the traditional forecasts of penetration, saturation, population growth, etc., as well as information about the costs of any relevant conservation measure. The module weights load shapes from the load-shape module to determine the time profile of use for each customer class. All of the time profiles are then aggregated to forecast the composite response of the end-use to the conservation program under analysis.

In general the data needs of the end use module are the greatest of the three modules that comprise the new software tool. These data requirements can be broken into three classes:

- baseline information

- input forecasts

- costs of demand-side strategies.

Each of these classes of data calibrates a different portion of the model's function.

Baseline values define the end-use as it is used in the first period of the model. Important factors defining the end-use portion of total demand are specified in this class of data, including:

- initial end-use saturation

- initial conservation penetration

- annuat kwh used by the end-use

- total number of households.

One element of the input forecasts are forecasts of how the baseline will change over the analysis period. A second element is how the implementation of a conservation strategy will change the mix of important variables over 
time. Together these provide the basis for the dynamic component of the mofel. How peak and energy demand change over time is determined principally by thase forecasts.

Cost data has elements of both groups. If the conservation "project" is tied to a forecasted element then it is forecasted as well. For example, a program that subsidizes higher efficiency water heaters has costs directly related to the number of high-efficiency water heaters installed. On the ot er hand, installation of capacitance on a feeder is a "once-and-for-all" proje:t. In either case, the interest payments and financing strategy for the prograin or project will need to be considered. These aspects are part of the analysis provided by the end-use module.

\subsubsection{Summary Module}

The final template is the summary module, which aggregates across each of the end-use modules. This module reports the summary of all the effects implied by the programs being examined in the end-use and load-shape module:;. The aggregate effects are reported at both the customer-class and system levels.

In addition to an overview of the system, the sumnary module provides a cost/benefit analys is of the conservation measure versus the proposed construction alternative. This requires inputs on a variety of aspe. 's relating to the proposed construction project including:

- cost of the conservation program elements

- conservation measure purchase cost

- maintenance costs

- incentive payments

- cost of the construction scenario

- amount financed

- length of financing period

- interest rate on bonds

- inflation rate.

This information is used by the sumnary module to compute two financial calculations. The first calculates gains and losses of the conservation program 
from the consumer, utility, and society perspectives. The second compares the conservation versus construction net present values.

The summary module brings together the information about the components of the system. By aggregating the results generated in each of the end-use modules, a picture of the system under the two different scenarios is obtained. This aggregate system picture, in conjunction with the construction alternative financial information, allows the available choices to be ranked.

After the new software was developed, it was calibrated by using it to reconsider aspects of the Toledo-Wren Test Case.

\subsection{TOLEDO-WREN TEST CASE APPLICATION OF THE NEW SOFTWARE}

Application of the software to the Toledo-Wren test case showed that the difficulties encountered using commercially-available software could be redressed. The new software was able to handle improved efficiencies of replacement appliances and allowed easy tracking of the peak hour shifting that typically occurs in studies of this type.

Formatting the analysis to fit the new software required separation of the data into different segments than those used with the commercial software. This was accomplished by outlining the requirements of the different modules and fitting the data described in Section 3.0 into that structure. Figure 7.1 shows the basic alignment of the new software when applied to the Toledo-Wren case as outlined below.

\subsubsection{Residential Sector}

Fitting the residential sector into the model involves three load-shape modules and three end-use modules. First, each of the three load shapes must be entered into a load-shape template. Secondly, the appropriate housing stock information must be entered into the appropriate end-use template.

Each of the residential load shapes was assigned its own load-shape module. The space heat module contained both the ceramic space heat and conventional space heat load shapes. The water heat module contained both the controlled and uncontrolled shapes. Shapes were assumed to be the same for all of the housing types. In the more general case, such as when there are different 


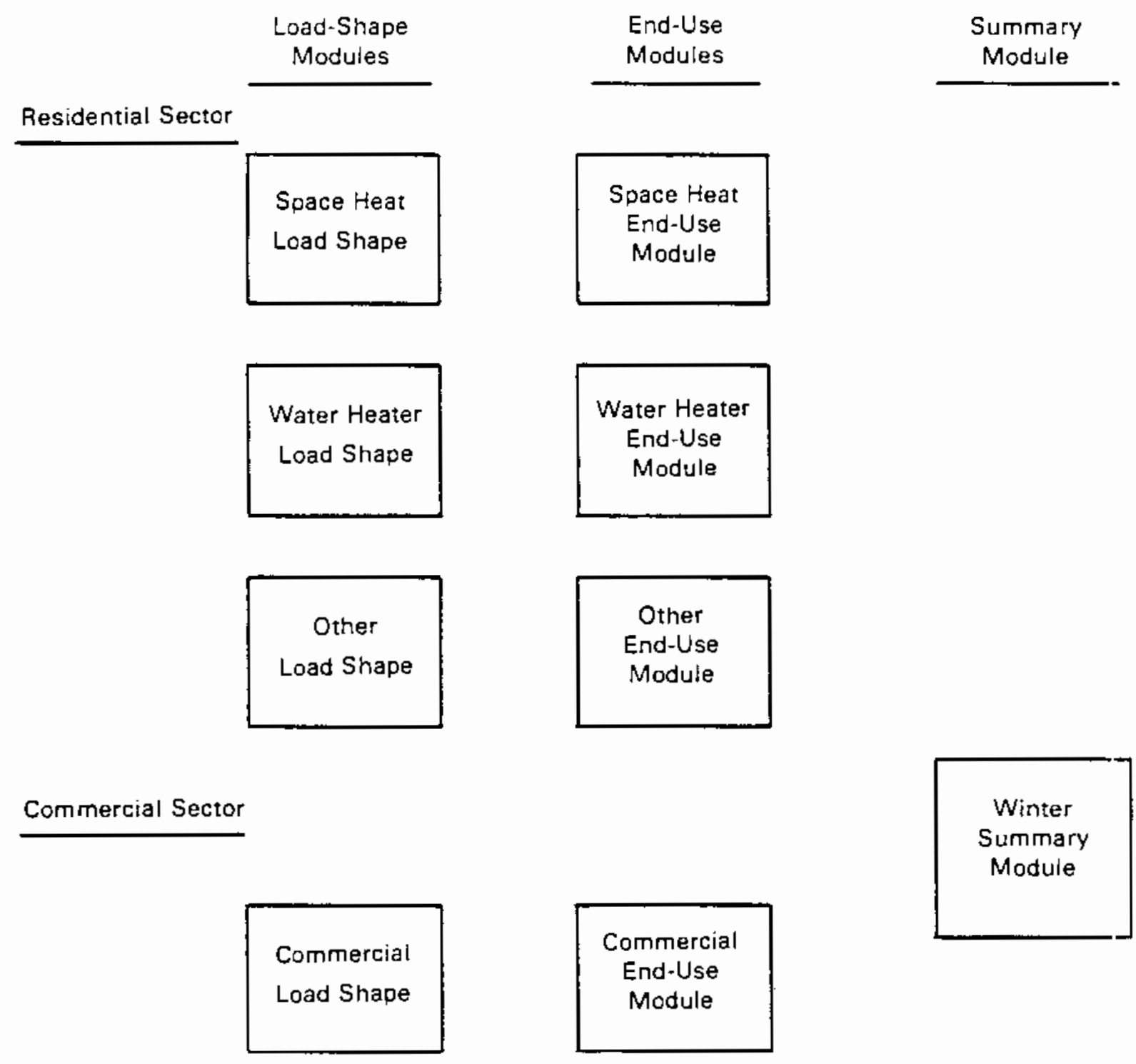

Industrial Sector

Industrial

Load Shape

Industrial

End-Use

Module

FIGURE 7.1. Basic Alignment of New Software Modules when Applied to the Toledo-Wren Test Case 
load shapes for each of three residential housing types, there would be a different load-shape module for each load shape. As the basic load shape data for this analysis was from a triple metering experiment, there were three load-shape modules: space heat, water heat, and other shapes.

Corresponding to each load shape module was an end-use module. The enduse module apportions the load shape to each housing class. The apportionment uses several factors. These include the number of customers, their growth scenarios, and the penetration rate of the conservation program. These factors were allocated by housing class. In this case study there were three housing classes which were treated separately. These included the post-1975 construction new homes, pre-1975 construction homes, and mobile homes as the housing classes. Each of the apportionment factors was entered for each of the housing classes. Section 5.0 describes the housing classes in detail. The specification of data and levels of aggregation were the same as those used in the earlier analysis.

\subsubsection{Commercial Sector}

The commercial sector was treated in less detail than the residential sector. Instead of three classes of customers the commercial sector was divided into two classes. These were a small commercial class and a large commercial class. The split allowed the bimodal nature of the commercial sector in the Toledo-Wren area to be captured while retaining the simpler data needs implied by the more aggregated framework.

In the commercial sector there was a single module containing a composite commercial load shape. This load shape included all the electrical uses of the building. If the analysis had been considering complex conservation program which included several different aspects of a commercial operation then greater detail in the specification of the components of building load shape would have been appropriate.

Since there is only a single load shape, there is a single end-usc module. The end-use module included a small, and a large commercial class. The information provided for each of the commercial classes was the same as that provided in the residential end-use modules. 


\subsubsection{Industrial Class}

The industrial class was modeled as a monolithic block using a single load shape and class of industrial plant. The reasons for this extreme leve: of aggregation were straightforward, and perhaps, not unique to this analysis. The greatest difficulty was in handling the proprietary nature of the energy demands of the plants in the Toledo-Wren area. There are only a few users and the way their production processes worked could be revealed by a detaileed examination of their load data. This aspect worked against the precision available in the analysis. Also, in this test case, the load factor of the industrial sector was well over $90 \%$. This suggested that there was not much shape to be concerned with in this sector of demand. As a result, it allowed the industrial class as a whole to be represented by a simple load shape.

Configuration of the end-use and load-shape modules needed to account for these differences in the modeling of the industrial class. Since average energy consumption by an industrial plant was not proprietary, it was possitile to build the mock industrial system to mimic the real industrial system closely. The industrial class, as a whole, was calibrated to closely match aggregate forecasts for industrial growth in the service area.

The load-shape and end-use modules are the only ones that do not have customers and shapes that can be identified with the actual area of study. The role of these two modules is to function as a placeholder for the industrial class and allow the system loads to be forecast. Since there was to be no industrial conservation program, this approach is satisfactory for analyzins residential program effects on system load. It does, however, imply that conclusions about the industrial sector are more tenuous than those for the other sectors.

\subsubsection{Sulmary Module}

There were four sunmary modules, one for each of the seasons. In general, system capacity is a binding constraint only during the peak season. Untess a complete yearly picture of the utilities' load is needed only the peak season module will be of interest. In this case the winter season was the peak season. 
Summer, fall, and spring demands all have substantial system capacity available to meet load growth. Therefore, these seasons were ignored in the balance of this study.

The summary module used the results of the five end-use modules and aggregated the data to two levels. The first aggregation was to the customer-class level, providing residential, commercial, and industrial summaries. In the case of the Toledo-Wren case study the commercial and industrial sectors had only one end-use module. Their summaries are the same as their respective end-use module. The residential summary aggregated the space-heater, waterheater, and other-uses modules to create the customer class summary. The second way the data was sumnarized was to the system level by aggregating the five end-use modules.

Another feature of this software is the capacity to perform cost benefit analysis of the conservation program versus the construction alternative. The summary module took information concerning the cost of the construction alternative and compared it with the cost of the conservation program as specified in the end-use module.

\subsection{NEW ANALYTICAL RESULTS}

More satisfactory results were obtained from the application of the new software to the Toledo-Wren case than were achieved with the previous use of commercially-available software. The new software allowed fine-tuning of preliminary program specifications that was prohibitively expensive in the earlier analysis. The results using the new software are summarized below.

\subsubsection{Ceramic Space Heater Program}

The ceramic heater program was modified from the approach described in Section 5.0 by shifting the recharge cycle back one hour. This was found to be sufficient, in the new analysis, to avoid producing an artificial early morning peak. As a result, the delays that are chievable with the program are substantial.

Figure 7.2 shows the forecasted peak by year for both the conservation and base case. A ceramic space heater program was found to extend the adequacy of 


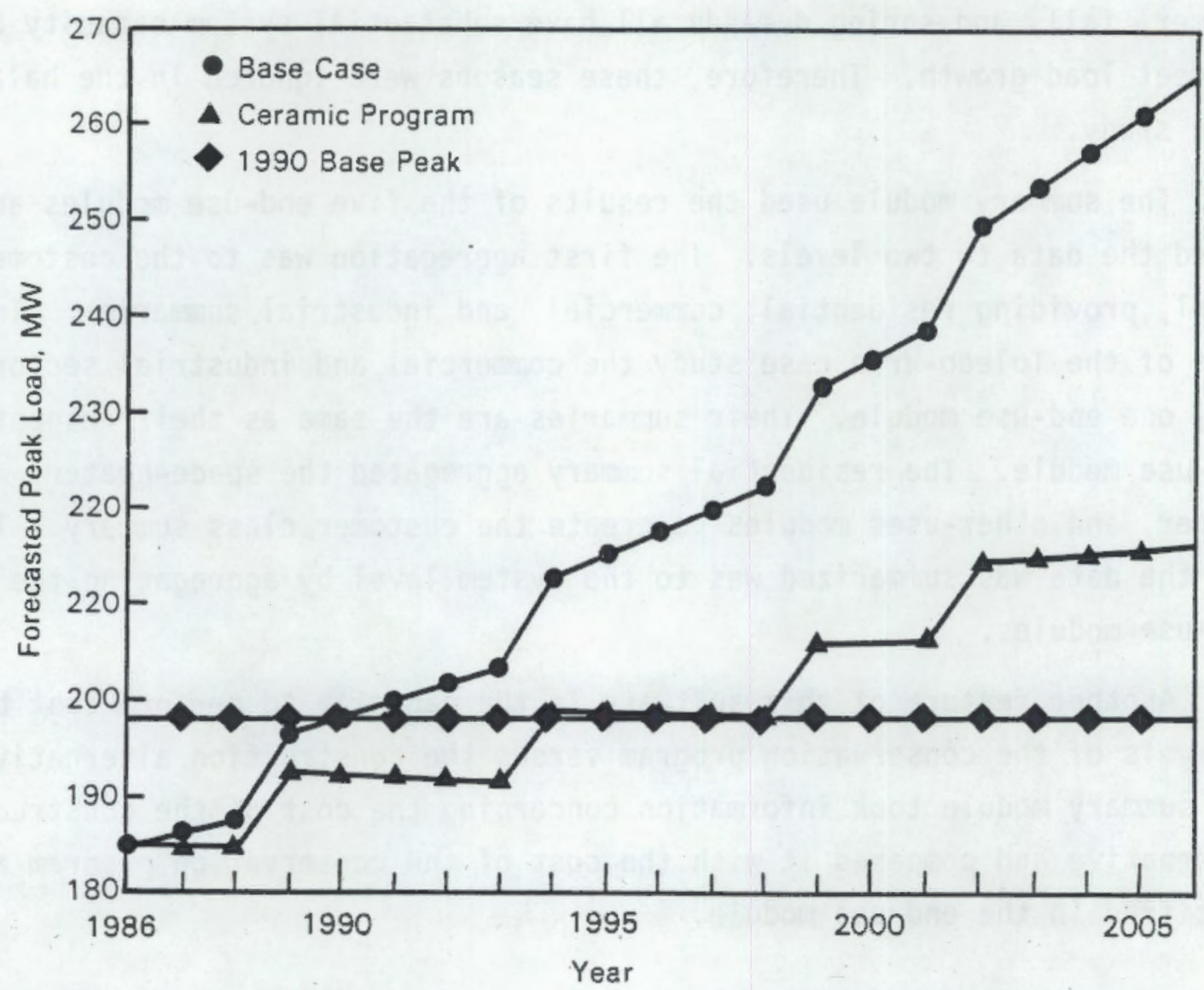

FIGURE 7.2. Peak Deferment Resulting from the Ceramic Room Heater Program

the existing transmission capacity by four years, to 1994, in the scenario considered. If the industrial forecast were to be reduced by one plant, which is not a large perturbation of the industrial model and its limitations, the capacity of the system could remain adequate until 1998. Given that industry in the area consists mainly of wood products plants, it seems likely that this scenario is a good deal more realistic. Therefore, the ceramic room heater program alone would be nearly sufficient to defer the construction project beyond the 10-year range of the BPA facility construction plan.

\subsubsection{Water Heater Control Program}

The second conservation measure reconsidered was the water heater control program. Figure 7.3 shows the effect of the water heater program on system demand. Water heater control holds the system peak below capacity for 7 years. 


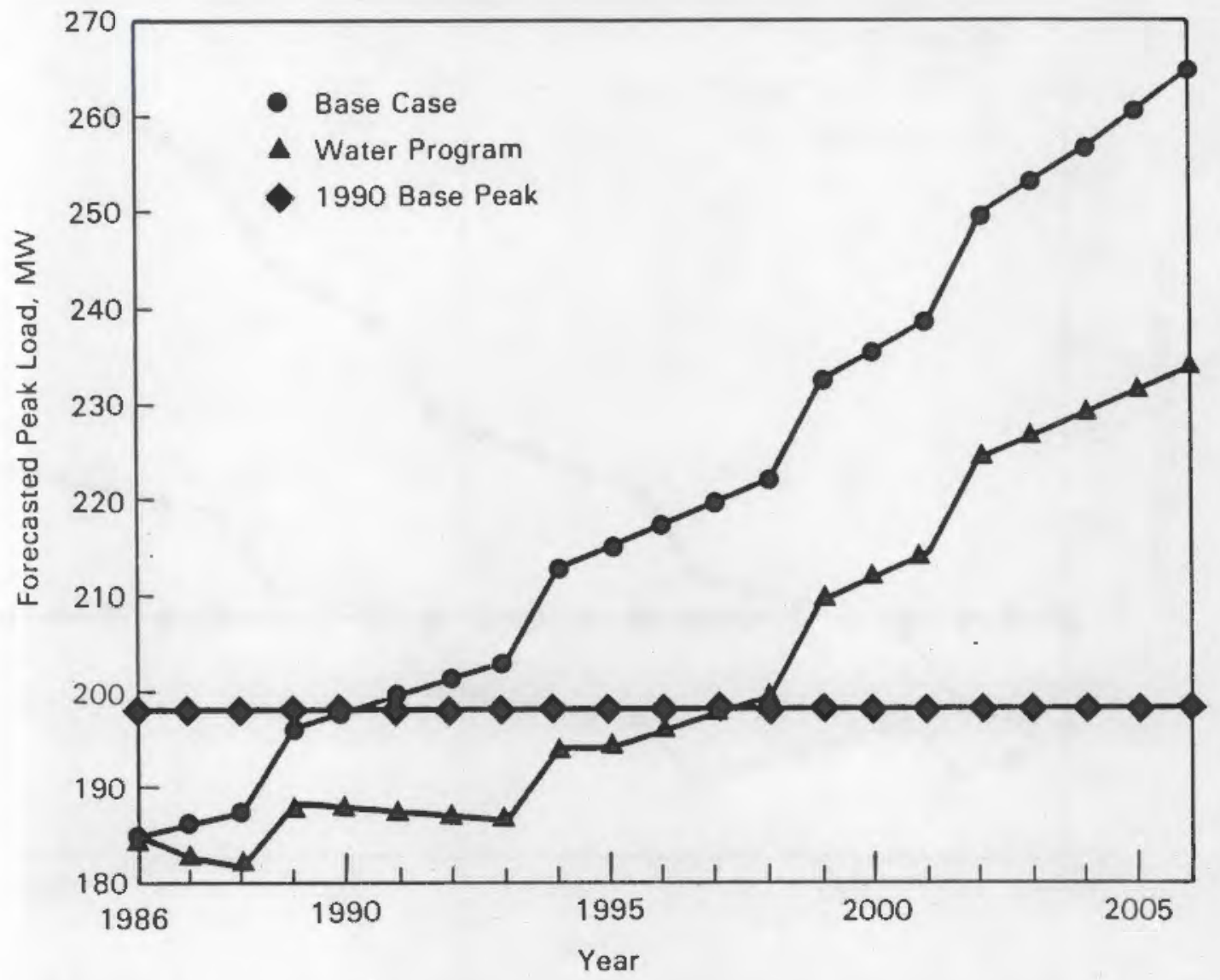

FIGURE 7.3. Peak Deferment Resulting from Water Heater Control Program

The delay is especially sensitive to the industrial or commercial forecast. One result not shown in Figure 7.3 is that the time of system peak shifts to 12:00 Noon. This is the result of payback from the program.

\subsubsection{Combined Water Heater and Ceramic Heater Programs}

The combined program of applying both the ceramic room heater and the water heater programs is represented in Figure 7.4. This program would permit a 9 -year delay in transmission facility construction. However, this result is sensitive to the industrial forecast. If a single plant is not brought on line during this period, the construction deferment could be extended to 12 years.

The time of the system peak also moves under this scenario. First the peak moves to $12: 00$ noon in 1994. It moves again to $1: 00 \mathrm{pm}$ in 1995 . The peak then remains at 1:00 pm for the remainder of the forecast period. 


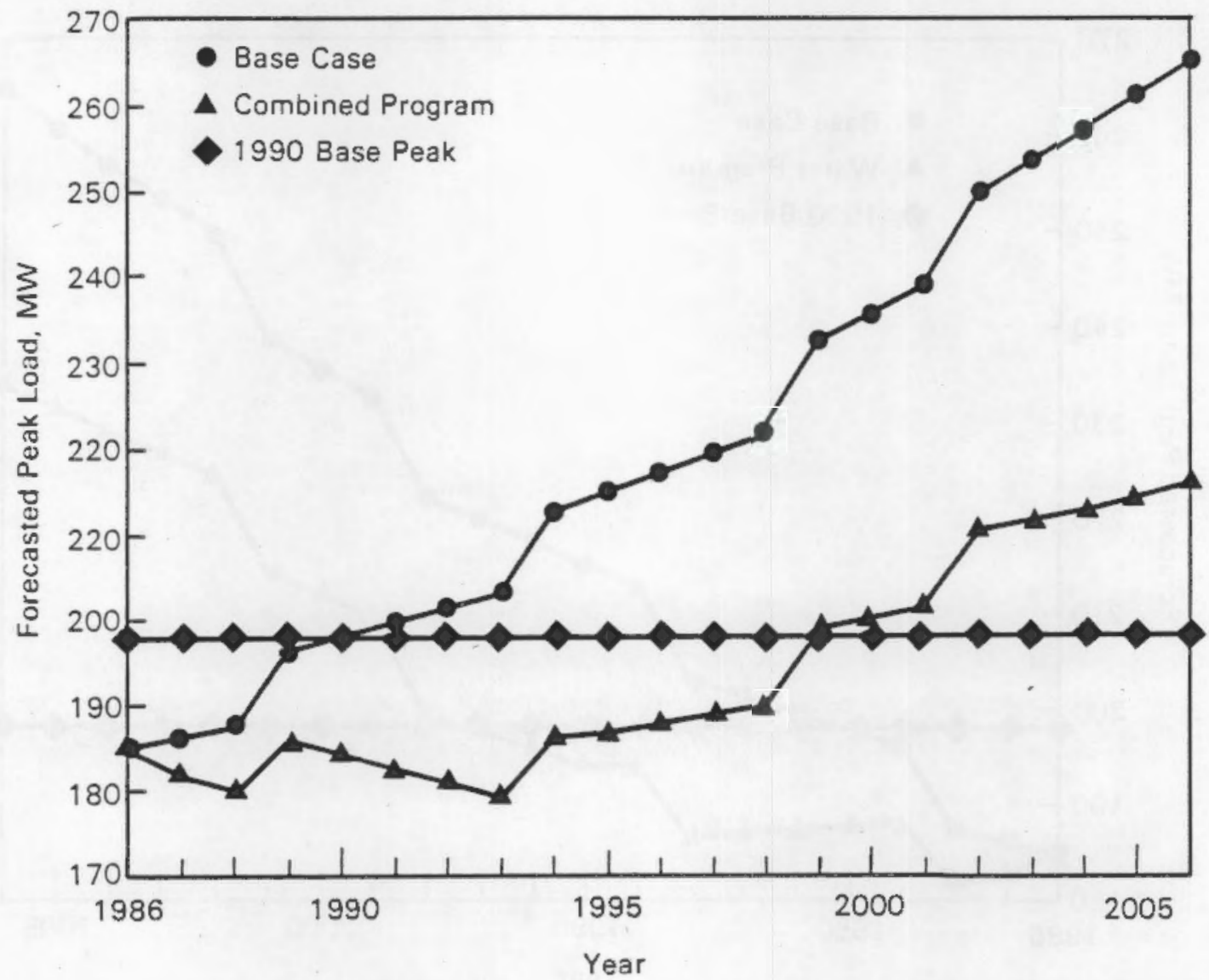

FIGURE 7.4. Peak Deferment Resulting from Combined Water Heater and Ceramic Heater Programs 


\subsection{CONCLUSIONS}

This research has focused on the problem of evaluating the potential of conservation to delay the construction of transmission and distribution facilities. The work was based on two requirements. One was the need to develop a methodology that is technically appropriate. The second was to develop an approach reflecting the empirical realities of utility planning. The end products of this effort are a benchmark analys is of a Pacific Northwest test case and a software tool that can be used to analyze other cases.

Methodology development was the primary objective and was realized by the development of an end-use based CILOC assessment technique. End-use load shapes coupled with forecasts of housing, appliance forecasts, and given conservation programs can be used to assess the ability of each program to delay the need for construction of T\&D facilities. The focus in the first phase of the project was on working with commercially-available software. In the second phase the lessons learned were applied to develop a new software system. The new software fully exploits the knowledge gained in the first phase. This results in the development of a powerful flexible end-use assessment tool.

Exercising the new software shows that there is considerable room for conservation programs to displace T\&D construc:ion. Deferments range from 4 to 9 years. The ceramic room heater program generated a delay of 4 to 8 years depending on the industrial forecast. A water heater control program delayed the need for additional capacity for 7 years. This result did not vary much with the industrial forecast. A combined program delayed the need for construction 9 years. The size of system peak demand was fairly sensitive to conservation programs.

One use of the Toledo-Wren Test Case examined in this study is as a benchmark that indicates considerable potential for additional CILOC deferments throughout the Pacific Northwest. The community that was studied was representative of many towns in the region. Given the widely varying terrain, weather, industrial base, and energy needs it seems likely that strategic conservation could have an important role in the efficient distribution of energy resources in the Pacific Northwest. 


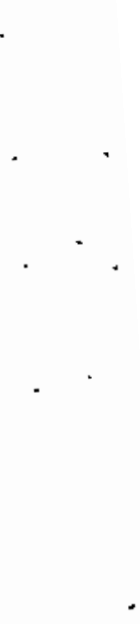


APPENDIX A

CASE STUDY DATA SOURCES 
APPENDIX A

CASE STUDY DATA SOURCES

This Appendix describes data sources used for the case study. The Appendix has two parts. The first part is an abbreviated catalogue of holdings, with short reference titles and catalogue numbers. The second part provides short abstracts and any cross-references.

Data sources were assigned catalogue numbers dependent on their content area according to the following scheme:

\begin{tabular}{|c|c|}
\hline Content Area & Catalogue \#Prefix \\
\hline Central Lincoin Utility & CENL \\
\hline Consumers Power Utility & CONP \\
\hline \multicolumn{2}{|l|}{ Utility Data Subclassification: } \\
\hline Residential & $R-$ \\
\hline Commercial & $. C-$ \\
\hline Industrial & $.1-$ \\
\hline Other & $. E T C-$ \\
\hline Transmission Line(s) & WIRES - \\
\hline Bend-Albany Residential End-Use Study & B-A.NDUS- \\
\hline Load Management & LD.MET - \\
\hline Load Data Transferability & LD.XFR - \\
\hline Load Forecasting & $\mathrm{LO} .4 \mathrm{CR}-$ \\
\hline Weather Observations & WOBS- \\
\hline Selection of Load Management Options & TASK.12- \\
\hline Software \& Documentation & MODL- \\
\hline
\end{tabular}


CATALOG NUMBER

CENL.ETC-001

CENL.ETC-002

CENL.ETC-003

CENL.ETC-004

CENL.ETC -005

CENL.ETC-006

CENL. I -007

CENL.ETC-008

CENL .ETC-009

CENL.ETC-010

CENL.ETC-011

CENL.ETC-012

CENL.RCI -013

CENL.ETC -014

CENL.ETC -015

CENL.ETC-016

CENL.ETC-017

CENL.R-018
TITLE

BPA Form 980 of $6-82$

Load \& Sys. Plans '78 - ' 98

Financial Statements $12 / 83 ; 7 / 84$

System Loads by Delivery Pts 1983

Space \& Water Heat Saturations

Questions for Utilities

Proposed Industrial Conservation Acquisitions BPA Wholesale Bill (8-22-85)

Load Estimate Review (3-29-85) for ' 84

Provisional Load Est. + Attchmts 9/25/85

BPA Form 980, Total \& Toledo (9/30/85);

\& Toledo trends (graphs)

Financial Forecast - $d t$ 'n of load '89 - '94

NW. Natural Gas Co. Service Area Map

Contact Folder

Lincoln County Facts for Business \& Industry

Newport-Toledo Phone Book

Housing Characteristics 70, ' 80 Census

\# Residential accounts 
CATALOG NUMBER

CONP.ETC-001

CONP.ETC-002

CONP.ETC-003

CONP.ETC-004

CONP.ETC-005

CONP.ETC-006

CONP.ETC -007

CONP.RC -008

CONP .ETC-009

CONP. R-010

CONP .ETC -011

CONP.R -012

CONP .ETC -013

CONP.R , C, ETC -014

CONP.ETC -015

CONP. I -016

CONP . RCI -017

CONP.ETC-018
TITLE

BPA Form 980 of 10-81

Transmission \& Distribution Tech $Q$.

Long Range Plan dated $2 / 84$

Construction Work Plan '83-'84

1983 Annual Report

System Load by Delivery Pts. - ' 83

System Maps

Space \& Water Heat Saturations

BPA Form 980 of $7-85$

Lifesty?e Characteristics \& Sample $Q$.

System Energy reqs; sales (graphs)

Residential End-Use Forecast; power reqs;

\# customers; NRG use v. HDDs

Questions to ask utilities

Load Growth Analysis by location \& by

customer class

Power Reqs. Study of $5 / 85$

Proposed Industrial Conservation Acquisitions Nw. Natural Gas Co. Service Area

Contact Folder

TRANSMISSION LINE(S)

HIRES

CATALOG NUMBER WIRES-001

TITLE

BPA 10 Year Transmission Dvpt Plan

BEND-ALBANY

$\mathrm{B}-\mathrm{A}$

CATALOG NUMBER

TITLE

B-A. NDUS -001

$B-A-002$

Blank PP\&L survey + data access info. Load Curves for Bend-Albany 
CATALOG NUMBER

TI TLE
LD .MGT -001
LD.MGT -002
$\frac{\text { Managing the Demand for Electricity }}{\text { Lakesand study; \& SCADA Description }}$
LD.MGT -003
Load Management overview
LD.MGT-004
EPRI Residential \& Comm. Technologies
LD.MGT-005
EPRI Cost-Benefit Analysis
LD.MGT -006
Customer Acceptance - DLC
LD.MGT -007
Evaluation of Systems \& Devices
LD.MGT-008
EPRI Technical Briefs

LOAD OATA TRANSFERABILITY

LD .XFR

CATALOG NUMBER

LD. XFR-D01

LD. XFR -002

LD. XFR -003
TITLE

Load Data Pool Feasibility

Load Shape Response Transfer

Load Data Transfer

LOAD FORECASTING

LO. 4CR

CATALOG NUMBER

LD. 4CR -001

LD . 4CR-002

LD.4CR-004

LD.4CR-005 v.1

LD.4CR -005

LD. 4CR -005

L.D .4CR -005

LD. 4CR -010

LD. 4CR -011

LD. 4CR -012

LD . 4CR -013
TITLE

Statistical Analysis of Load Data Forecasting Distr. Loads w/clustering Vol. 2 Load Forecasts \& Distr. PIan'g Regional Load Curve Models: DRI Spec. RLCM: QUERI Model Specification RLCM: Scenario \& Forecasts w/DRI

RLCM: Forecasts \& more $w /$ QUERI Bjornstad \& Tepel Hausman re: purchase of durables Dubin \& MCFadden 1984

Lifestyle Effects on Residential NRG Use 
CATALOG NUMBER

WOBS -001

WOBS-002

WOBS -003

WOBS -004

WOBS -005

W0BS-006

W0BS -007

WOBS -008

W0BS -009

WOBS -010
TITLE

Salem hourly surface $1 / 1 / 83-12 / 31 / 84$

Redmond hrly. surface $1 / 1 / 83+12 / 31 / 84$

Newport surface weather $1 / 1 / 83-12 / 31 / 84 \& 30$ yr. summary

Corvallis hourly temp. + dewpoints $4 / 83-4 / 85$

Redmond hrly. surface weather $8 / 84-4 / 85$

Newport Minimum Temps. - Historical

Newport degree days 1961 - 1/85

Mag tape Salem $1 / 1 / 77-4 / 3 / 85$

Mag tape Redmond $1 / 77$ - 4/85

Microfiche Newport 1/1/77-12/31/82

SELECTION OF LOAD MANAGEMENT OPTIONS

TASK12.

CATALOG NUMBER

TITLE

TASK12-001

High Potential Load Management Options for the BPA: Working Paper

SOFTUARE AND DOCUMENTATION

MODL

CATALOG NUMBER

MOOL -002

MODL -003

MODL -004

MODL -005

MODL -006

MODL -007
TITLE

PROC CONTENTS LABEL FOR B-A DATA

LOADCALC

MICROCAST - Residential

MICROCAST - Commercial

SAS User's Guide \& Documents

SHAPES 


\section{OETAILS ON HOLOINGS}

CATALOGUE NUMBER: CENL.ETC-1

OATE RECEIVEO: $\quad 1984$

CONTENT AREA: Central Lincoln

SUBCLASSIFICATION:

REFERENCE TITLE: BPA Form 980 Dated 6-82

ABSTRACT: Load Data and Forecasts 1974-1992. Number of customers, kWh per customer by class, sales, losses. System loads by points of delivery. Sales data for large power customers.

CROSS-REFERENCE(S):

CATALOGUE MUMBER: CENL.ETC-2

OATE RECEIVED: $\quad 1984$

CONTENT AREA: Central Lincoln

SUBCLASSIFICATION:

REFERENCE TITLE: A Load Study of System Planning Study for FY 1985-FY 1933

ABSTRACT: $\quad H i s t o r i c a l ~ d a t a$ and some system planning by customer class and by delivery points. System maps.

CROSS-REFERENCE (S) : 


\section{DETAILS ON HOLDINGS}

CATALOGUE NUMBER: CENL.ETC-3

DATE RECEIVED: $\quad 1984$

CONTENT AREA: Central Lincoln

SUBCLASSIF ICATION:

REFERENCE TITLE: Financial Statements: $12 / 83 ; 7 / 84$

ABSTRACT :

CROSS-REFERENCE (S):

CATALOGUE NUMBER: CENL.ETC-4

DATE RECEIVED: $\quad 1984$

CONTENT AREA: Central Lincoln

SUBCLASS IF ICATION:

REFERENCE TITLE: System Loads by Point of Delivery Through 1983

ABSTRACT. Printout from BPA.

CROSS-REFERENCE (S): 


\section{DETAILS ON HOLDINGS}

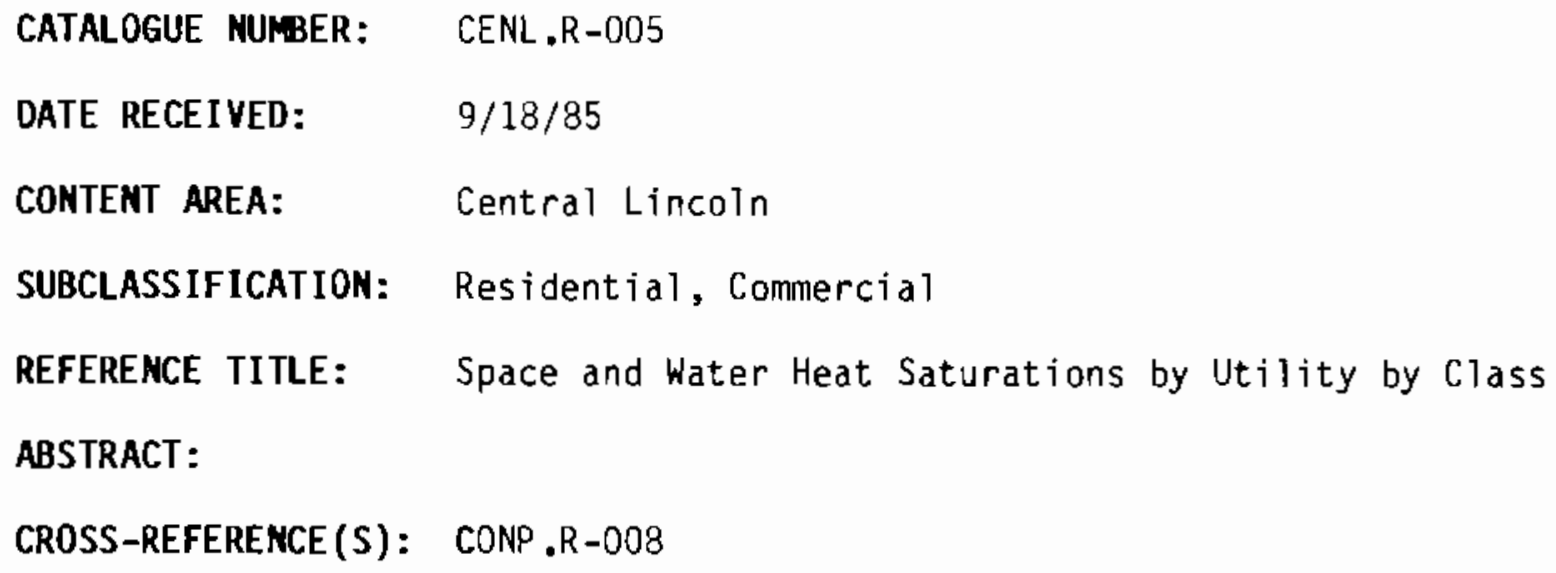


CATALOGUE NUMBER: CENL, I -007

DAIE RECEIVED: $\quad 10 / 14 / 85$

CONIENT AREA: Central Lincoln

SUBCLASSIFICATION: Industrial

REFERENCE TITLE: Proposed Industrial Conservation Acquisitions

ABSTRACT: $\quad$ Sponsor's proposal cover sheets with program/project

summary, location and company, time schedule, anticipated energy savings and project costs. Some customers may not be served by Central Lincoln.

CROSS-REFERENCE(S): COMP . I -016
CATALOGUE NumBER: CENL.ETC-008
DATE RECEIVED: $\quad 10 / 14 / 85$
CONTENT AREA: Central Lincoln
SUBCLASSIFICATION: Other
REFERENCE TITLE: BPA wholesale Power Bill (8/22/95)
ABSTRACT :
Wholesale power bill to Central Lincoln including meter readings and loss factors by point of delivery (for period ending $8 / 22 / 85$ ).

CROSS-REFERENCE(S): 


\section{DETAILS ON HOLDINGS}

CATALOGUE NUMBER: CENL.ETC-009

DATE RECEIVED: $\quad 10 / 14 / 85$

COHTENT AREA: Central Lincoln

SUBCLASSIFICATION: Other

REFERENCE TITLE: Load Estimate Review for 1984 Dated 3/29/85

ABSTRACT: $\quad$ One page sumary of CY 1984. Number of customers, kwh fer customer and energy sales 1) by customer class and 2) by points of delivery.

CROSS-REFERENCE(S): CENL .ETC-004, CENL .ETC-001

CATALOGUE NUMBER: CENL.ETC -010

DATE RECEIVED: $\quad 10 / 14 / 85$

CONTENT AREA: Central Lincoln

SUBCLASSIFICATION:

REFERENCE TITLE: Provisional Load Estimate and Attachments (9/25/85)

ABSTRACT: $\quad$ BPA Form 980 of $6 / 82$ and written comments about those forecasts and also about anticipated future of Toledo paper mili.

CROSS-REFERENCE (S): CENL.ETC-001, CENL.ETC-011 


\section{DETAILS ON HOLDINGS}

CATALOGUE NUMBER: CENL.ETC-011

DATE RECEIVED: $\quad 10 / 14 / 85$

CONTENT AREA: Central Lincoln

SUBCLASSIFICATION:

REFERENCE TITLE: BPA Form 980, Total and Toledo (9/30/85), and Toledo Trends (graph)

ABSTRACT: $\quad$ Updated Form 980 shows Toledo, and system. Graph is labeled.

CROSS-REFERENCE(S): CENL.ETC-010, CENL.ETC-001

CATALOGUE NUMBR: CENL.ETC-012

DATE RECEIVED: $\quad 10-14 / 85$

CONTENT AREA: Central Lincoin

SUBCLASSIFICATION: Other

REFERENCE TITLE: Financial Forecast - Determination of Lc i, 1989-1994

ABSTRACT: $\quad$ Number of consumers, average use per consumer, annual sales and annual power requirements, by customer class.

CROSS-REFERENCE (S) : 


\section{DETAILS ON HOLDINGS}

CATALOGUE NUMBER: CENL.RCI -013

DATE RECEIVED: $\quad 10 / 14 / 85$

CONTENT AREA: Central Lincoln

SUBCLASSIFICATION: Residential, Commercial, Industrial

REFERENCE TITLE: Area Served by Northwest Natural Gas Company

ABSTRACT: Map shows locations of gas lines.

CROSS-REFERENCE(S): CONP.RCI-017, CENL.RC-005

CATALOgue Numbr: CENL.ETC-014

DATE RECE IVED: $\quad 10 / 17 / 85$

CONTENT AREA: Central Lincoln

SUBCLASSIFICATION: Other

REFERENCE TITLE: Contact Folder

ABSTRACT: Utility Contact Information

CROSS-REFERENCE (S): 


\section{DETAILS ON HOLOINGS}

CATALOGUE NUMBER: CENL.ETC-015

DATE RECEIVED: $\quad 12 / 13 / 85$

CONTENT AREA: Central Lincoln

SUBCLASSIFICATION: Other

REFERENCE TITLE: Facts for Business and Industry from Newport Chamber of Commerce

ABSTRACT: Lincoln County facts (industries, employment, schools, motels, population) including a Toledo map and Newport brochure. Obtained from Greater Newport Chamber of

Commerce, 555 S.W. Coast Highway, Newport, OR 97365

CROSS-REFERENCE ( $S$ ):

CATALOGUE NUMBER: CENL-016

DATE RECEIVED: $\quad 12 / 18$

CONTENT AREA: Central Lincoln

SUBCLASSIFICATION: $\quad$ ETC

REFERENCE TITLE: Newport-Toledo Phone Book

ABSTRACT:

CROSS-REFERENCE(S): 


\section{DETAILS ON HOLDINGS}

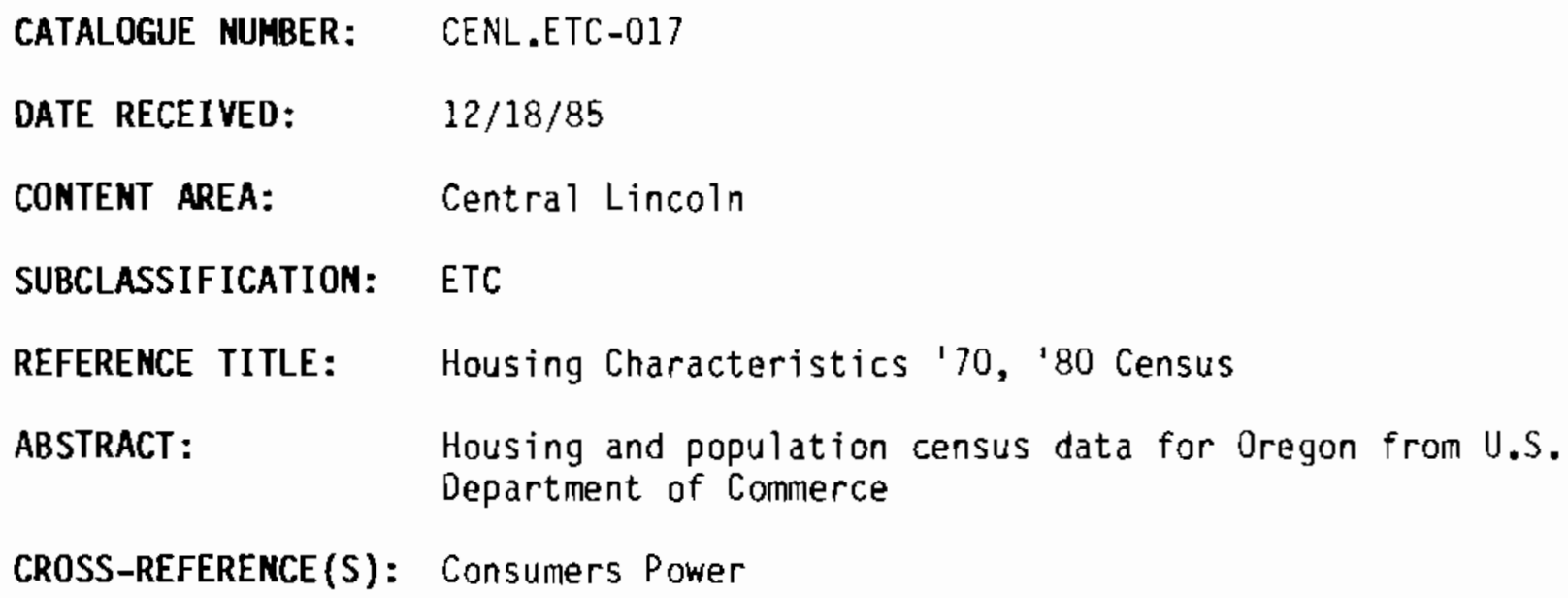


CATALOGUE NUMBE: CONP.ETC-1

DATE RECEIVED: $\quad 1984$

CONTENT AREA: Consumers Power

SUBCLASS IF ICATION:

REFERENCE TITLE: $\quad$ 8PA Form 980 Dated 10/81

ABSTRACT: $\quad$ Load data and forecasts 1974-1991. Number of customers, $\mathrm{kWh}$ per customer by class, sales losses. System loads by points of delivery. Sales data for large power customers.

CROSS-REFERENCE(S): CONP.ETC-009

CATALOGUE NUMBER: CONP.ETC-2

DATE RECEIVED: $\quad 1984$

CONTENT AREA: Consumers Power

SUBCLASSIFICATION:

i'FERENCE TITLE: Technical Questionnaire; Transmission and Distribution System

ABSTRACT: $\quad$ CSEI Task 3 questionnaire completely filled in; details feeders, transformers, substations, etc. Attachment estimates distribution system losses in different format.

CROSS-REFERENCE (S) : 
DETAILS ON HOLDINGS

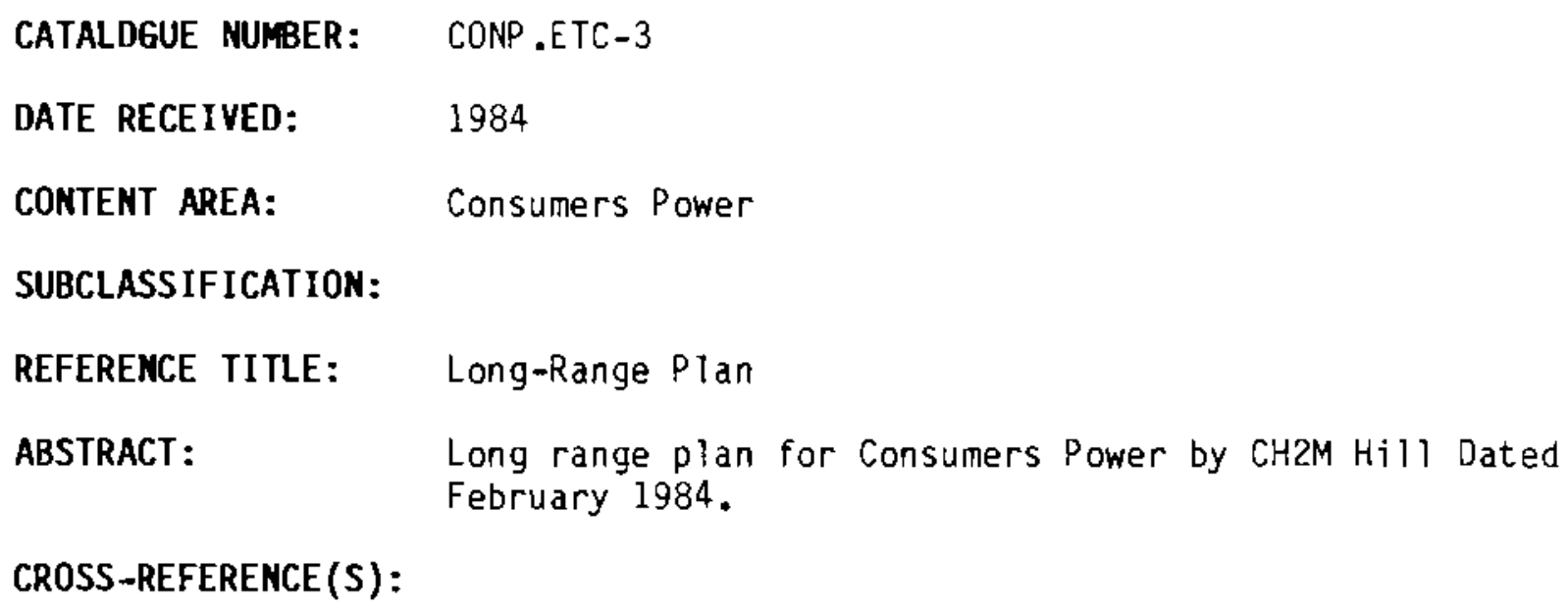

CATALOGUE NUMBER: CONP.ETC-4

DATE RECEIVED: $\quad 1984$

CONTENT AREA: Consumers Power

SUBCLASSIFICATION:

REFERENCE TITLE: Construction Work Plan 1983-1984

ABSTRACT: $\quad$ Maps and work plan 1983-1984. CROSS-REFERENCE (S): 


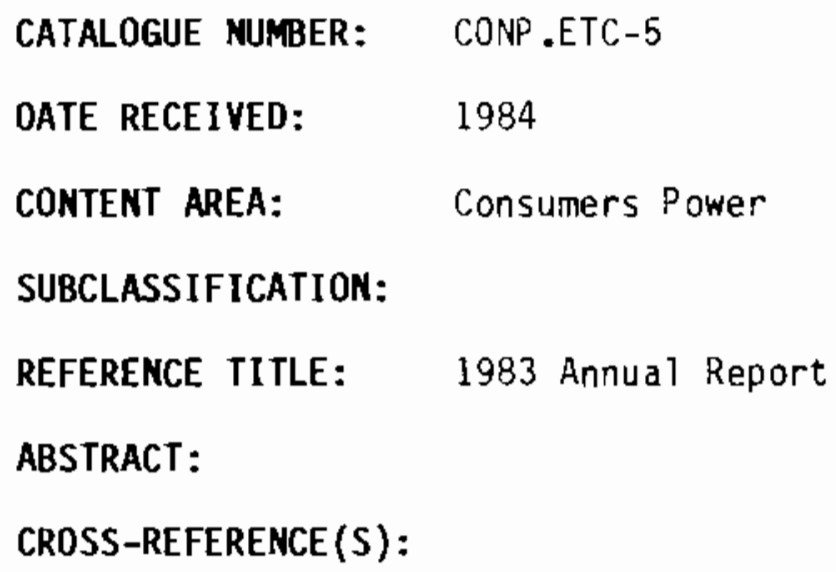

CATALOGUE NUMBER: CONP.ETC-5

DATE RECEIVED: $\quad 1984$

CONTENT AREA: Consumers Power

SUBCLASSIFICATION:

REFERENCE TITLE: 1983 Annual Report

ABSTRACT :

CROSS-REFERENCE (S):

CATALOGUE NUMBER: CONP.ETC-6

DATE RECEIVED: $\quad 1984$

CONTENT AREA: Consumers Power

SUBCLASSIFICATION:

REFERENCE TITLE: Systen Load by Points of Delivery Through 1983

ABSTRACT: $\quad$ BPA c c...puter readout.

CROSS-REFERENCE (S) : 


\section{DETAILS ON HOLOINGS}

CATALOGUE NUMBER: CONP . ETC -7

DATE RECEIVED: 1984

CONTENT AREA: Consumers Power

SUBCLASSIF ICATION:

REFERENCE TITLE: System Maps

ABSTRACT :

CROSS-REFERENCE(S):

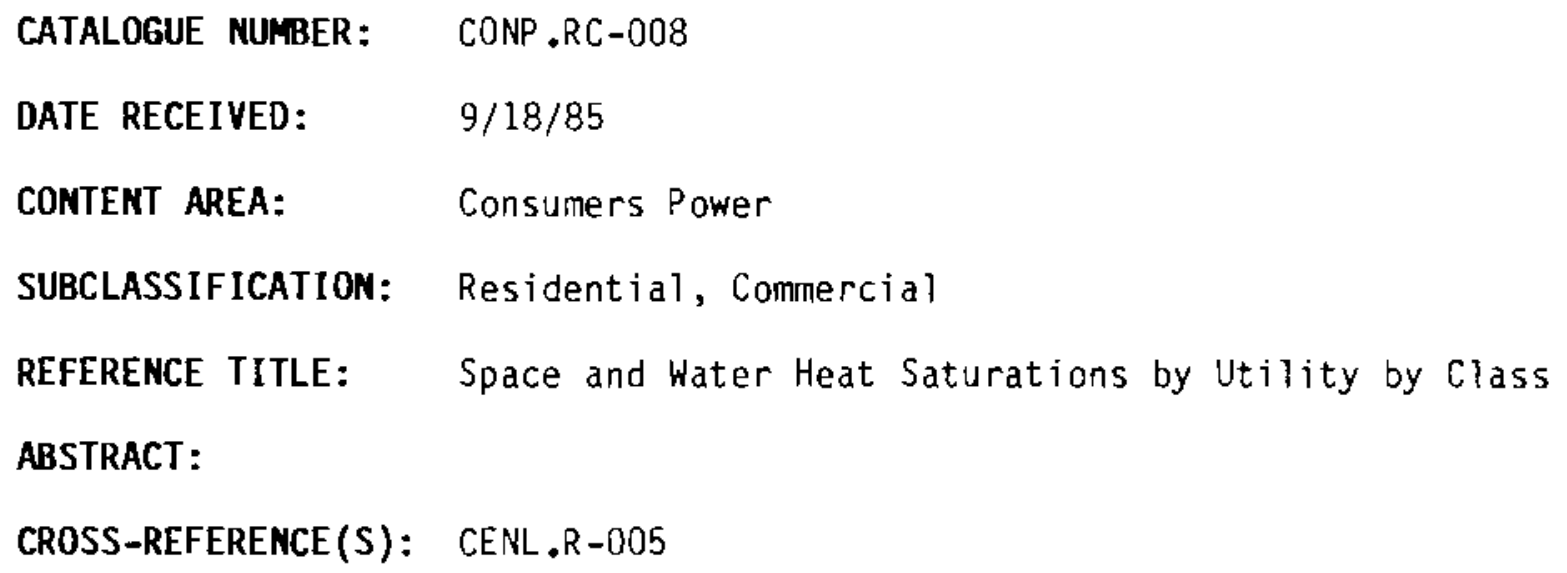

CATALOGUE NUMBER: CONP .RC-008

DATE RECEIVED: $\quad 9 / 18 / 85$

CONTENT AREA: Consumers Power

SUBCLASSIFICATION: Residential, Commercial

REFERENCE TITLE: Space and Water Heat Saturations by Utility by Class ABSTRACT :

CROSS-REFERENCE(S)：CENL .R-005 


\section{DETAILS ON HOLDINGS}

CATALOGUE NUMBER: CONP.ETC-009

DATE RECEIVED: $\quad 9 / 18 / 85$

CONTENT AREA: $\quad$ Consumers Power

SUBCLASSIF ICATION: $\quad 0$ ther

REFERENCE TITLE: BPA Form 980 of $7 / 85$

ABSTRACT: $\quad$ Load data and forecasts 1981-1995 and 2000 and 2005. Number of customers, kWh per customer by class, sales, losses. System loads by points of delivery. Sales data for large power customers.

CROSS-REFERENCE(S): CONP.ETC-001

CATALOGUE NUMBER: CONP.R-010

DATE RECEIVED: $\quad 9 / 18 / 85$

CONTENT AREA: Consumers Power

SUBCLASSIFICATION: Residential

REFERENCE IITLE: Lifestyle Characteristics and Sample Questionnaire

ABSTRACT: $\quad 1983$ Residential Customer Survey form, with a few pages of discussion.

CROSS-REFERENCE(S): 


\section{DETAILS ON HOLDINGS}

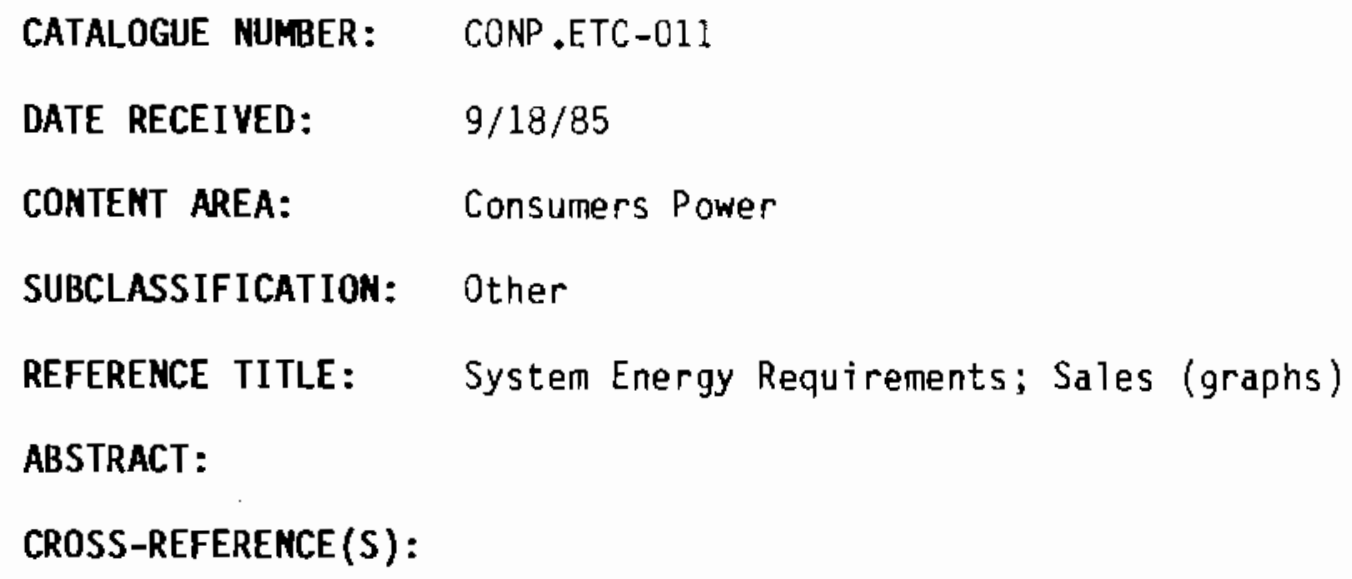




\section{DETAILS ON HOLDINGS}

CATALOGUE NUMBER: CONP.ETC-013

DATE RECEIVED: $\quad 10 / 14 / 85$

CONTENT AREA: Consumers Power

SUBCLASSIFICATION: Other

REFERENCE TITLE: Questions to Ask Utilities

ABSTRACT: $\quad J$. Englin's list of questions prepared for planned trip of 10/10. Compiled by $\mathrm{J}$. Englin from Task 13 staff.

CROSS-REFERENCE(S): CENL.ETC-006

CATALOGUE NUMBER: CONP.RC,ETC-014

DATE RECEIVED: $\quad 10 / 14 / 85$

CDNTENT AREA: Consumers Power

SUBCLASSIFICATION: Residential, Commercial, Other

REFERENCE TITLE: Load Growth Analysis by Location and by Customer Class

ABSTRACT: $\quad$ Set of labeled graphs with key figures hand written depicting load growth in the residential and commercial sectors and by substation.

CROSS-REFERENCE(S): CONP .ETC-011 


\section{DETAILS ON HOLOINGS}

CATALOGUE NUMBER: CONP.ETC-015

DATE RECEIVED: $\quad 10 / 14 / 85$

CONTENT AREA: Consumers Power

SUBCLASSIFICATION: Other

REFERENCE TITLE: Power Requirements Study (5/85)

ABSTRACT: $\quad G e n e r a l$ background information, recent trends in customers and energy sales, population and residential customers, as sumptions for the future, forecast by 1982 power reqs. study, appendices with forms. David Blake, author.

CROSS-REFERENCE (S):

CATALOGUE NUMBER: CONP.I-016

DATE RECEIVED: $\quad 10 / 14 / 85$

CONTENT AREA: Consumers Power

SUBCLASSIFICATION: Industrial

REFERENCE TITLE: Proposed Industrial Conservation Acquisitions

ABSTRACT: $\quad$ Sponsor's proposal cover sheets with program/project

summary, location and company, time schedule, anticipated energy savings and project costs. Some customers may not. be served by consumer power.

CROSS-REFERENCE(S)：CENL .I-007 


\section{DETAILS ON HOLDINGS}

CATALOGUE NUMBER: CONP-RCI-017

DATE RECEIVED: $\quad 10 / 14 / 85$

CONTENT AREA: Consumers Power

SUBCLASSIFICATION: Residential, Commercial, Industrial

REFERENCE TITLE: Area Served by Northwest Natural Gas Company

ABSTRACT: Map shows location of gas lines.

CROSS-REFEREMCE(S): CENL.RCI -013, COMP.RC-008

CATALOGUE NUmBER: CONP.ETC-018

DATE RECEIVED: $\quad 10 / 17 / 85$

CONTENT AREA: Consumers Power

SUBCLASSIF ICATIDN: Other

REFERENCE TITLE: Contact Folder

ABSTRACT: Utility contact information.

CROSS-REFERENCE (S) : 


\section{DETAILS ON HOLOINGS}

CATALDGUE NUMBER: WIRES-001

DATE RECEIVED: $\quad 10 / 17 / 85$

CONTENT AREA: Transmission Lines

SUBCLASSIFICATION: Toledo-Wren Addition

REFERENCE TITLE: BPA Transmission System Facilities 10-Yr. Development ' $85-{ }^{\prime} 94$

ABSTRACT: $\quad$ Study lists new facilities proposals by year of energization and by fiscal year new start. Toledo area reinforcement proposed for new start - tentatively FY 1987; Energization - 1989; Estimated Cost: $\$ 10,750,000$. Study by Branch of System Planning, Div. of System Engineering, BPA

CROSS-REFERENCE(S): JGD's notes - alternative costing $\$ 700 \mathrm{~K}$ could protect system from the major cost of a load exceeding safety limits.

CATALOGUE NUMBER: LD.MGT-1

Dh. RECEIVED: $\quad 10 / 14 / 85$

CONTENT AREA: Load

SUBCLASSIFICATION: Management

REFERENCE TITLE: Managing the Demand for Electricity (book)

ABSTRACT: $\quad$ Book on load management requested by $R$. Tepel. Full title: Managing the Demand for Electricity: Utility Market ing and Consumer Adoption of Residential Load Management. Published by North Carolina Alternative Energy Corporation

CROSS-REFERENCE (S): 


\section{DETAILS ON HOLDINGS}

CATALOGUE NUmBER: LD-MGT-2

DATE RECEIVED: $\quad 9 / 23 / 85$

CONTENT AREA: Load

SUBCLASSIFICATION: Management

REFERENCE TITLE: LAKESAND Study; and Integrated SCADA and LD MGT System

ABSTRACT :

First paper discusses load control from the perspective of an urban, municipally owned generating utility which peaks in the winter season. Second paper describes a technique to increase the effectiveness of load management. Published by Gilbert/Commonwealth/Tejas Controls, Inc.

CROSS-REFERENCE (S) :

CATALOGUE NUMBER: LD.MGT-3

DATE RECEIVED: $\quad 8 / 23 / 85$

CONTENT AREA: Load

SUBCLASSIFICATION: Management

REFERENCE TITLE: Load Management overview published by American Public Power Association

ABSTRACT: $\quad$ Overview of load control benefits, applicability, strategies, equipment, benefits and costs, and customer sensitivities. Three case studies. American Public Power Association, publishers. Gilbert/Commonwealth, authors.

CROSS-REFERENCE (S): 


\title{
DETAILS ON HDLDINGS
}

\author{
CATALOGUE NUMBER: LD.MGT-4 \\ DATE RECEIVED: $\quad 9 / 23 / 85$ \\ CONTENT AREA: Load \\ SUBCLASSIFICATION: Management \\ REFERENCE TITLE: $\quad$ EPRI Residentia? and Commercial Program in LD.MGT \\ Technology \\ ABSTRACT: $\quad$ Overview of the Load Management Technology Program \\ describing customer-side load management technology \\ development as well as related EPRI programs.
}

CROSS-REFERENCE (S):

CATALOGUE NUMBER: LD.MGT-5

DATE RECEIVED:

CONTENT AREA: Load

SUBCLASSIFICATION: Management

REFERENCE TITLE: Cost-Benefit Analysis of Load Management 0ptions

ABSTRACT: $\quad$ EPRI report (1980) not yet received.

CROSS-REFERENCE(S): 


\section{DETAILS ON HOLDINGS}

CATALOGUE MUMBER: LD.MGT-6

DATE RECEIVED:

CONTENT AREA: LOad

SUBCLASSIFICATION: Management

REFERENCE TITLE: Customer Acceptance of DLCS

ABSTRACT: $\quad$ EPRI report (1981) not yet received. Full title is

"Customer Acceptance of direct Load Controls Residential Water Heating and Air Conditioning."

CROSS-REFERENCE (S):

CATALOGUE NUMBER: LD.MGT-007

DATE RECEIVED: $\quad 10 / 17 / 85$ have

CONTENT AREA: Load Management

SUBCLASSIFICATION:

REFERENCE TITLE: Evaluation of Load-Man ement Systems and Devices

ABSTRACT: $\quad$ Two sections: 1) Communication and Load Control, including radio, ripple $\mathrm{PLC}$, Combo. radio and $\mathrm{PLC}$, telephone, local control, other systems; and 2) TES-

Thermal Energy Storage systems. EPRI EM-1423, TPS 78-807

Final Report $(6 / 80)$

CROSS-REFERENCE (S): 
CATALOGUE NUMBER: LD.MGT-008

DATE RECEIVED: $\quad 12 / 18 / 85$

CONTENT AREA: Load

SUBCLASSIFICATION: Management

REFERENCE TITLE: EPRI Technical Briefs

ABSTRACT: $\quad$ 1) report summary, marketing demand-side programs to improve load factor 2) Technical Brief (TB); dual-fuel heating systems 3) TB: central ceramic heat storage 4) TB: timers 5) TB: room ceramic heat storage 6) TB: programmable controllers 7) TB: slab heating 8) TB: appliance interlocks 9) TB: load management thermostats 10) TB: temperature-activated switches. R. Tepel brought back reports from Chicago conference on load management.

CROSS-REFERENCE (S):

CATALOGUE NUMBER: LO.XFER-1

OATE RECEIVED:

CONTENT AREA: Load

SUBCLASSIFICATION: Data Transferability

REFERENCE TITLE: Load Data Pool Feasibility

ABSTRACT: $\quad$ EPRI report (1983) not yet received.

CROSS-REFERENCE (S): 


\section{DETAILS ON HOLDINGS}

CATALOGUE NUMBER: LD.XFER-2

DATE RECEIVED:

CDNTENT AREA: Load

SUBCLASSIFICATION: Data Transfer

REFERENCE TITLE: Analysis of Methods for Load Shape Response Transfer

ABSTRACT: $\quad$ EPRI report (1984) not yet received.

CROSS-REFERENCE (S):

CATALOGUE NUMBER: LD,XFER-3

DATE RECEIVED:

CONTENT AREA: Load

SUBCLASSIFICATION: Data Transfer

REFERENCE TITLE: Analysis of Methods for Load Data Transfer

ABSTRACT: $\quad$ EPRI report (1984) not yet received.

CROSS-REFERENCE(S): 


\section{DETAILS ON HOLDINGS}

CATALDGUE NUMBER: L.C. 4 CR -1

DATE RECEIVED:

CONTENT AREA: LOad

SUBCLASSIF ICATION: Forecasting

REFERENCE TITLE: Selected Statistical Methods Re: Load Research Data

ABSTRACT: $\quad$ EPRI report (1984) not yet received.

CROSS-REFERENCE (S):

$\begin{array}{lll}\text { CATALDGUE NUMBER: } & \text { LD.4CR-2 } \\ \text { DATE RECEIVED: } & 1984 \\ \text { CONTENT AREA: } & \text { Load } \\ \text { SUBCLASSIFICATION: } & \text { Forecasting } \\ \text { REFERENCE TITLE: } & \text { Forecasting Distribution System Loads - with Clustering } \\ \text { ABSTRACT: } & \begin{array}{l}\text { Use of curve shape clustering for forecasting; H. L. } \\ \text { Willis, et al. authors. American Power Conference ig82. }\end{array} \\ \text { CROSS-REFERENCE(S): } & \end{array}$




\section{DETAILS ON HOLDINGS}

CATALOGUE NUMBER: LD.4CR-004

DATE RECEIVED: $\quad 10 / 17 / 85$

CONTENT AREA: LOad

SUBCLASSIFICATION: Forecasting

REFERENCE TITLE: Research into Load Forecasting and Distribution Planning Vol. 2

ABSTRACT: Comparison of data collection Methods for load, land-use and demographic data; comparison of models for load forecasting and modeling, discussion of capabilities and limits. EPRI EL-1198. Vol. 2 Proj. 570-1 Final report $(10 / 79)$.

CROSS-REFERENCE $(S): R$. Tepe l

CATALOGUE NUMBER: LD.4CR-005

DATE RECEIVED: $\quad 10 / 17 / 85$

CONTENT AREA: LOad

SUBCLASSIFICATION: Forecasting

REFERENCE TITLE: Regiona) Load Curve Models

ABSTRACT: $\quad$ 1) Specification and estimation of DRI model (Data Resource, Inc.) 2) QUERI's model specification, estimation and validation (Quantitative Economic Research, Inc.) 3) Scenario and forecast using the DRI mode? 4) QUERI's model long-run forecasts and sensitivity analysis. EPRI EA-1672, Project $1008,1981$.

CROSS-REFERENCE(S): R. Tepel 


\section{DETAILS OH HOLDINGS}

CATALOGUE NUMBER: LD. 4 CR -010

DATE RECEIVED: $\quad 10 / 17 / 85$

CONTENT AREA: Load

SUBCLASSIFICATION: Forecasting

REFERENCE TITLE: Draft "Comparative Analysis of Errors in Long-Term Econometric Forecast for Aggregate and Component Variables."

ABSTRACT: $\quad$ Bjornstad, David J. (ORNL) and Richard C. Tepel (Battel a PNWD), authors.

CROSS-REFERENCE ( $S)$ :

CATALOGUE NUMBER: LD. 4 CR -011

DATE RECEIVED: $\quad 10 / 17 / 85$

CONTENT AREA: LOAd

SUBCLASSIFICATION: Forecasting

REFERENCE TITLE: Hausman, Jerry A. "Individual Discount Rates and the Purchase and Utilization of Energy-Using Durables." The? Bell Journal of Economics. p. 33-54.

ABSTRACT :

CRDSS-REFERENCE ( $S$ ): 
CATALOGUE NURBE: $\quad$ LC. 4 CR -012

DATE RECEIVED: $\quad 10 / 17 / 85$

CONTENT AREA: LOad

SUBCLASSIFICATION: Forecasting

REFERENCE TITLE: Dubin, Jeffrey A. and Daniel L. McFadden. 1984. "An Econometric Analysis of Residential Electric Appliance Holdings and Consumption." Econometrica. Vol. 52, No. 2, p. 345-362. Re: Avoiding specification errors when the demand for durables and their use are related decisions by the consumer.

ABSTRACT :

CROSS-REFERENCE (S): LD.4CR-003

CATALOGUE NUMBER: LD.4CR-013

DATE RECEIVED: $\quad 10 / 21 / 85$

CONTENT AREA: Load

SUBCLASSIFICATION: Forecasting

REFERENCE TITLE: Lifestyle Effects on Residential Energy Use

ABSTRACT: $\quad$ Analysis of a large data set to identify lifestyle trends that should be accounted for in retrofit performance research. An Oak Ridge National Laboratory report.

CROSS-REFERENCE (S) : 


\section{DETAILS ON HOLDINGS}

CATALOGUE NUMBER: B-A.NDUS-001

DATE RECEIVED: $\quad 10 / 16 / 85$

CDNTENT AREA: $\quad$ Bend-Albany

SUBCLASSIFICATION: End-Use Survey

REFERENCE TITLE: Blank PP\&L Survey and Data Access Information

ABSTRACT: $\quad$ Letter from PP\&L to Mike Warwick that accompanied data tapes with SAS data set and survey results. Includes

blank copy of survey and documentation of the tapes.

CROSS-REFERENCE(S): MODL-002

CATALOGUE NUMBER: B-A-002

DATE RECEIVED: $\quad 10 / 29 / 85$ received

CONTENT AREA: Bend-Albany

SUBCLASSIFICATION:

REFERENCE TITLE: Load Curves for Bend-Albany

ABSTRACT: $\quad$ Weekday observations from Bend and Albany, 11/83 - 2/84

hourly space heat load, hourly total load, water heat

load, by type of heating system, means and standard

errors. Graphic format. BPA contact: Eric Westland.

CROSS-REFERENCE(S): 


\section{DETAILS ON HOLDINGS}

CATALOGUE NUMBER: WOBS-001

DATE RECEIVED: $\quad 10 / 22 / 85$

CONTENT AREA: Weather Observations

SUBCLASSIFICATION:

REFERENCE TITLE: Salem Hourly. Surface Weather 1/1/83-12/31/84

ABSTRACT: $\quad$ Tape and documentation for Station 24232, 9-track, 1600 bpi, ASCII, unlabeled, fixed length, 318 ch/record, block 20. From National Climatic Data Center. $(a)$

CROSS-REFERENCE(S): WOBS-002 (same tape)

(a) U.S. Department of Commerce National Oceanic and Atmospheric Administration, National Environmental Satellite, Data and Information Service, Federal Building, Asheville, North Carolina 28801.

CATALOGUE NUMBER: WOBS-002

DATE RECEIVED: $\quad 10 / 22 / 85$

CONTENT AREA: Weather Observations

SUBCLASSIFICATION:

REFERENCE TITLE: Redmond Hourly Surface Weather 1/1/83-12/31/84

ABSTRACT: $\quad$ Tape and documentation for Station 24230, 9-trach, 1600 bpi, ASCII unlabeled, fixed length, $318 \mathrm{ch} /$ record, block 20. From National Climatic Data Center.

CROSS-REFERENCE(S): WOBS-001 (same tape) 


\section{DETAILS ON HOLDINGS}

CATALOGUE NUMBER: WOBS -3

DATE RECEIVED: $\quad 10 / 10 / 85$

CONTENT AREA: Weather Observations

SUBCLASSIFICATION:

REFERENCE TITLE: Newport Surface Weather Observations 1/1/83-12/31/84 anc 30-yr. Summary

ABSTRACT: $\quad$ Surface weather observations ( 7 obs/day). From National Climatic Data Center.

CROSS-REFERENCE (S):

CATALOGUE NUMBER: WBOS-4

DATE RECEIVED: $\quad 10 / 8 / 85$

CONTENT AREA: Weather Observations

SUBCLASSIFICATION:

REFERENCE TITLE: Corvallis Hourly Tempe :ture and Dewpoints 4/83-4/85

ABSTRACT: $\quad$ Hygrothermographs of Corvallis surface weather. Provided by Oregon State Climatologist in Corvallis, Oregon.

CROSS-REFERENCE (S) : 


\section{DETAILS ON HOLDINGS}

CATALOGUE NUMBER: WOBS -5

DATE RECEIVED: $\quad 10 / 11 / 85$

CONTENT AREA: Weather Observations

SUBCLASSIFICATION:

REFERENCE TITLE: Redmond Hourly Surface Weather 8/84-4/85

ABSTRACT: $\quad$ Surface weather observations for Redmond. Data source:

National Climatic Data Center.

CROSS-REFERENCE(S): WOBS - (other Redmond data, some overlap).

CATALOGUE NU:BBER: WDBS-006

DATE RECEIVED: $\quad 10 / 15 / 85$

CDNTENT AREA: Weather Observations

SUBCLASS IFICATION:

REFERENCE TITLE: Newport Minimum Temperatures - Historical

ABSTRACT: Minimum temperatures and date of occurrence for Newport, Oregon (and some other Oregon locations) 1949-1983.

CROSS-REFERENCE (S): 


\section{DETAILS ON HOLDINGS}

CATALOGUE NUMBER: WOBS-007

DATE RECEIVED: $\quad 10 / 15 / 85$

CONTENT AREA: Weather ODservations

SUBCLASSIFICATION:

REFERENCE TITLE: Newport Degree Days 1961-1/85

ABSTRACT: $\quad$ Degree days by month 1961-1/85 with some missing data in earliest years.

CROSS-REFERENCE (S):

CATALOGUE NUMBER: WOBS -008

DATE RECEIVED: $\quad 11 / 5 / 85$

CONTENT AREA: Weather Observations

SUBCLASSIFICATION:

REFERENCE TITLE: Mag Tape Salen $1 / 1 / 77-4 / 3 / 85$

ABSTRACT: $\quad$ Surface weather observations every third hour for Salem from 1977-1980. Hourly from 1/181 - April 185. Source: National Ciimatic Data Center.

CROSS-REFERENCE (S): 
CATALOGUE NUMBER: WOBS-009

DATE RECEIVED: $\quad 11 / 5 / 85$

CONTENT AREA: Weather Observations

SUBCLASSIFICATION:

REFERENCE TITLE: Mag Tape Redmond 1/77-4/85

ABSTRACT: $\quad$ Surface weather observations for Redmond every third hour from 1977 - 7/31/81. Hourly from 8/1/81 - April 1985, 9track, 1600 bpi, ASCII, unlabeled, 80 block 10.

CROSS-REFERENCE (S) :

CATALOGUE NUMBER: WOBS-010

DATE RECEIVED: $\quad 11 / 5 / 85$

CONTENT AREA: Weather Observations

SUBCLASSIFICATION:

REFERENCE TITLE: Microfiche Newport $1 / 1 / 77-12 / 31 / 82$

ABSTRACT: $\quad$ One page per day for the six years surface weather. From the National Climatic Data Center.

CROSS-REFERENCE (S): 


\section{DETAILS ON HOLDINGS}

CATALOGUE NUMBER: MODL-0D2

DATE RECEIVED: $\quad<10 / 14 / 85$

CONTENT AREA: Software and Documentation

SUBCLASSIFICATION:

REFERENCE TITLE: PROC Contents Label for Bend-Albany Data

ABSTRACT: $\quad$ Computer printout of variables in SAS data set, e.g., income, number of children per household, demographic data. Also data for Albany and Bend.

CROSS-REFERENCE (S) : B-A.NDUS-001

$\begin{array}{ll}\text { CATALOGUE NUMBER: } & \text { MODL }-003 \\ \text { DATE RECEIVED: } & 9 / 85 \\ \text { CONTENT AREA: } & \text { Software and Documentation }\end{array}$

SUBCLASSIFICATION:

REFERL ":E TITLE: LOADCALC

ABSTRACT: Documentation and software. Software analyses base case: versus some conservation measure and 1) does a cost benefit analysis comparing the options, and 2) forecast load over time. Also called "Load Curve Synthesis System" Version 3.0. By AEG.

CROSS-REFERENCE(S): 


\section{DETAILS ON HOLOINGS}

CATALOGUE NUMBER: MODL-004

OATE RECEIVED: $\quad 9 / 85$

CONTENT AREA: Software and Documentation

SUBCLASSIF ICAT ION:

REFERENCE TITLE: Microcast-Residential

ABSTRACT: $\quad$ Documentation and model provide an end-use load forecasting system for the residential sector

(Version 2.0). By AEG.

CROSS-REFERENCE(S):

CATALOGUE NUMBER: MODL-005

OATE RECEIVEO: $\quad 9 / 85$

CONTENT AREA: Software and Documentation

SUBCLASSIFICATION:

REFERENCE TITLE: Microcast-Comercial

ABSTRACT: $\quad$ Documentation and model provide an end-use load

forecasting system for the commercial sector

(Version 2.1). By AEG.

CROSS-REFERENCE(S): 


\section{DETAILS ON HOLDINGS}

CATALOGUE NUMBER: MODL -006

DATE RECEIVED: Have

CONTENT AREA: Software and Documentation

SUBCLASSIFICATIOH:

REFERENCE TITLE: SAS Users Guide and Documentation

ABSTRACT: $\quad$ Oocumentation of the model and data sets being used as source for socioeconomic characteristics. Source: SAS Institute, Inc., Cary, North Carolina.

CROSS-REFERENCE(S): MODL-001, MODL-002

\section{CATALOGUE NUMBE: TASK12-001}

OATE RECEIVED: $\quad 11 / 4 / 85$

CONTENT AREA: $\quad$ Task 12

SUBCLASS IFICATION:

REFERENC-TITLE: High Potential Load Management Options for the BPA

ABSTRACT: Summary of LM options reviewed, selection criteria, limitations of the selection process, and LM options identified as high potential. PNL - Task 12.

CROSS-REFERENCE (S): 
PNL -5931

UC-95

\section{DISTRIBUTION}

No. of

Copies

OFFSITE

30 E. D. Westman MS/KES

Bonneville Power Administration P.0. Box 3621

Portland, OR 97208

2 DOE Technical Information Center

\section{ONSITE}

2 DOE Richland Operations Office

J. J. Sutey

D. R. Segna
No. of

Copies

30 Pacific Northwest Laboratory

J. W. Callaway

C. A. Counts

R. F. Darwin

J. G. De Steese (10)

J. E. Englin (5)

P. L. Hendrickson

M. S. Klan

A. J. Lyke

J. J. Tawil

R. C. Tepel

Publishing Coordination MH (2)

Technical Report Files (5) 


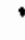

\section{.}

